\title{
Digital health for optimal supportive care in oncology: benefits, limits, and future perspectives
}

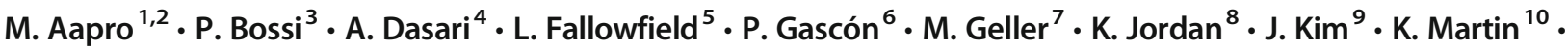 \\ S. Porzig ${ }^{11}$
}

Received: 2 December 2019 / Accepted: 18 May 2020 / Published online: 12 June 2020

(C) The Author(s) 2020

\begin{abstract}
Background Digital health provides solutions that capture patient-reported outcomes (PROs) and allows symptom monitoring and patient management. Digital therapeutics is the provision to patients of evidence-based therapeutic interventions through software applications aimed at prevention, monitoring, management, and treatment of symptoms and diseases or for treatment optimization. The digital health solutions collecting PROs address many unmet needs, including access to care and reassurance, increase in adherence and treatment efficacy, and decrease in hospitalizations. With current developments in oncology including increased availability of oral drugs and reduced availability of healthcare professionals, these solutions offer an innovative approach to optimize healthcare resource utilization.

Design This scoping review clarifies the role and impact of the digital health solutions in oncology supportive care, with a view of the current segmentation according to their technical features (connection to sensors, PRO collection, remote monitoring, selfmanagement in real time...), and identifies evidence from clinical studies published about their benefits and limitations and drivers and barriers to adoption. A qualitative summary is presented.

Results Sixty-six studies were identified and included in the qualitative synthesis. Studies supported the use of 38 digital health solutions collecting ePROs and allowing remote monitoring, with benefits to patients regarding symptom reporting and management, reduction in symptom distress, decrease in unplanned hospitalizations and related costs and improved quality of life and survival. Among those 38 solutions 21 provided patient self-management with impactful symptom support, improvement of
\end{abstract}

Key message Digital solutions with ePROs and self-management can be incorporated in supportive care in oncology practice and provide benefits to: patients, e.g., reduced symptom burden and distress, increased symptom reporting, improved overall survival; healthcare professionals, with targeted patient management; payors, potentially with reduced supportive care-related costs and hospitalizations.

M. Aapro

maapro@genolier.net

1 Medical Oncology, Genolier Cancer Center, Clinique de Genolier, Genolier, Switzerland

2 Institut Multidisciplinaire d'Oncologie (IMO), Clinique de Genolier, Case Postale (PO Box) 100, 1 Route de Muids,

CH-1272 Genolier, Switzerland

3 Department of Medical Oncology, University of Brescia, Brescia, Italy

4 Department of Gastrointestinal Medical Oncology, Division of Cancer Medicine, MD Anderson Cancer Center, Houston, TX, USA

5 Sussex Health Outcomes Research \& Education in Cancer (SHORE-C), Brighton \& Sussex Medical School, University of Sussex, Brighton, UK
6 Department of Hematology-Oncology, Hospital Clínic de Barcelona, University of Barcelona, Barcelona, Spain

7 Gynecologic Oncology, Department of Obstetrics, Gynecology and Women's Health (OBGYN), University of Minnesota, Minneapolis, MN, USA

8

Department of Medicine, Haematology, Oncology and Rheumatology, Heidelberg University Hospital, Heidelberg, Germany

9 Medical Oncology, Yale University School of Medicine, New Haven, CT, USA

10 Gyneco-oncology, Barnes-Jewish Hospital, St. Louis, MO, USA

11 Medical Oncology, Fox Chase Cancer Center, Philadelphia, PA, USA 
QoL, usefulness and reassurance. Principal challenges are in developing and implementing digital solutions to suit most patients, while ensuring patient compliance and adaptability for use in different healthcare systems and living environments.

Conclusions There is growing evidence that digital health collecting ePROs provide benefits to patients related to clinical and health economic endpoints. These digital solutions can be integrated into routine supportive care in oncology practice to provide improved patient-centered care.

Keywords Digital therapeutics · Integrative oncology · Symptom monitoring · Self-management $\cdot$ Patient-reported outcomes . eHealth

\section{Introduction}

The International Agency for Research on Cancer estimated that in 2018, there were 18.1 million new cancer cases worldwide and 9.6 million cancer-related deaths [1]. A global surveillance report suggests a trend toward increased survival [2], with some cancers progressing to chronicity. However, the total burden of new cancer cases is increasing, and new therapies are generally more costly [3]. Additionally, more drugs are available in oral formulations for home administration, with reduced face-to-face surveillance by healthcare professionals (HCPs). Novel approaches for optimal patient management that allow containment of healthcare costs are urgently needed [4].

The new approaches should focus on patient-centered care with integration of tumor-directed treatment and patient-directed supportive and palliative care throughout the disease journey $[5,6]$. The goals of management are to achieve improvements in not only overall survival (OS) but also patientreported outcomes (PROs) such as quality of life (QOL) [7], fewer emergency department visits, and self-reported improvements in symptoms [7, 8].

The intensive development over recent years of therapies with novel mechanisms of action, including moleculartargeted therapies, immuno-oncology therapies, and precision radiation oncology, has transformed the oncology treatment landscape $[9,10]$. These advances have increased the complexity of treatment (combination of therapies) and required modifications in the patient pathway (oral treatment intake at home versus hospitalization) to ensure quality care. The realworld toxicity profile of novel agents may not always correlate with that observed in clinical trials and may result in unanticipated toxicities $[11,12]$. Increased availability of oral therapies for home administration results in less healthcare supervision during treatment, whereas the prolonged use of such treatments as long-term maintenance may be associated with the emergence of new toxicities [13]. Therefore, careful monitoring of adverse events (AEs) during self-administration of treatments at home is becoming essential to facilitate prompt intervention to reduce their severity and duration.

Patients must therefore manage symptoms and treatmentrelated side effects without direct medical supervision; home administration of anticancer treatments also increases the chance of nonadherence and administration errors by patients [14]. With immunotherapeutic treatments, the timely identification of toxicities is crucial since many symptoms may improve with prompt intervention [15]. Additionally, a potential shortage in oncology services and workforce linked to the increasing cancer incidence and complexity of cancer treatments [16] has highlighted the need for new strategies to ensure that all patients receive optimal treatment and care throughout the continuum of disease.

Advances in digital communications and medical technologies have led to the digitalization of healthcare [17]. Increased access and uptake of such technologies among physicians and patients yields large amounts of potentially usable data, which, in the context of electronic health records (EHRs), forms an important part of physicians' decision-making. Self-reported data is extensively used in healthcare. Patient-level data provide real-world medical information, with opportunities for improved clinical decision-making, patient empowerment, improved health outcomes, and cost reductions [18-20]. However, patient confidentiality and compliance with local and global data privacy regulations need to be ensured.

\section{Digital health definitions with focus on digital therapeutics}

Digitalized healthcare comprises eHealth, telemedicine, telemonitoring, and digital therapeutics (Fig. 1).

The terms digital health, telehealth, and eHealth are interchangeable and are defined as the provision of healthcare services supported by telecommunications or digital technology to improve or support healthcare services. eHealth solutions can be part of each step of the healthcare process (i.e., prevention, diagnosis, decision-making, treatment/intervention, and follow-up).

Telemedicine represents medical services provided remotely to patients by HCPs using telecommunications platforms. Healthcare activities, such as patient evaluation, diagnosis, or treatment, are performed by HCPs without the need for inpatient consultation, although the legal status of such consultations varies according to jurisdiction [21].

Telemonitoring is the use of digital technology to frequently or continuously monitor patients' vital signs or any other 
eHealth

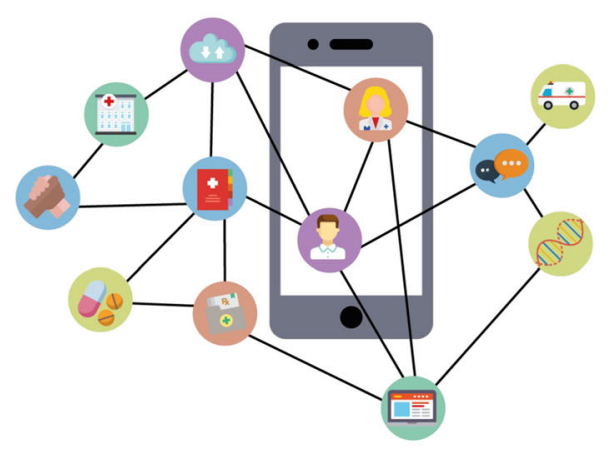

Telemedicine

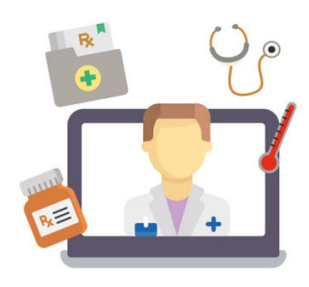

Telemonitoring

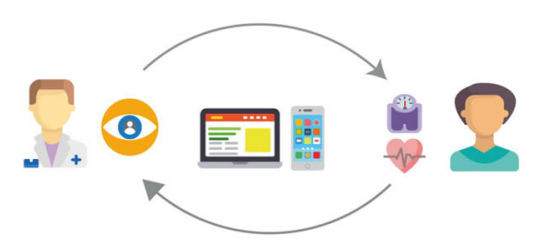

Digital therapeutics

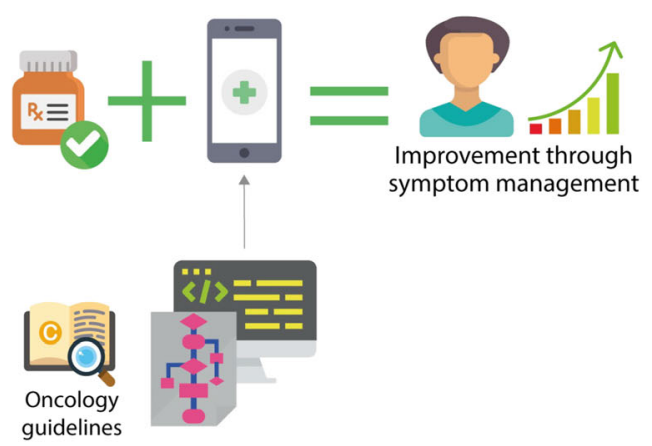

Fig. 1 Digital health definitions

symptoms. The information is assessed remotely by HCPs to inform the patient and caregivers about the actions needed for appropriate symptom management and treatment advice.

Digital therapeutics embed algorithms based on medical guidelines and best practices, which transform collected data into actionable insights, with the objective to bring value to evidence-based clinical outcomes (from clinical studies or real-world evidence). They may be used alone or in conjunction with drugs and medicinal products, medical devices, or other therapies, to enhance and support medical treatment. According to the risk level of the embedded algorithms, the digital therapeutics may be classified as medical devices. Depending on the regulatory status, they may be used on prescription only (prescription digital therapeutics).

A further technology of relevance to the broad concept of digitalized healthcare is artificial intelligence with capabilities of machine learning, which may be defined as the use of computer algorithms to make successful predictions about future events based on past experiences [22].

From a health outcomes perspective, digital health can be grouped into solutions connected to sensors or not and that capture ePROs to allow patient monitoring only or those that allow patient monitoring and symptom management by HCPs, covering remote areas, or symptom management by the patients themselves with or without real-time decision support for self-management. Patients receive individualized guidance, from a simple recommendation to call their $\mathrm{HCP}$, to a suggestion to begin a specific treatment intake.

\section{Supportive care for cancer patients definition and unmet needs}

The Multinational Association of Supportive Care in Cancer defines supportive care in cancer as "the prevention and management of the adverse effects of cancer and its treatment. This includes management of physical and psychological symptoms and side effects across the continuum of the cancer experience from diagnosis through treatment to post-treatment care. Enhancing rehabilitation, secondary cancer prevention, survivorship, and end-of-life care are integral to supportive care."'(About MASCC. mascc.org/about-mascc. Accessed January 11, 2019). Whereas there has been significant progress in anticancer treatment, improvements for optimal supportive care are still needed at all stages of the cancer treatment pathway [5]. Currently, supportive care interventions' assessment of patient QOL and medical outcomes remains limited, and QOL endpoints are insufficiently reported for clinical trials of novel therapies [23].

A number of evidence-based supportive care guidelines have been developed, but their implementation in routine clinical practice is suboptimal and the opportunity to improve control of symptoms is often forfeited [24]. This highlights the need for more optimal use of guidelines, for personalized and patient-centered care that is delivered in a timely manner.

Digital solutions present an opportunity to address certain unmet needs in prevention or management of adverse events in patients with cancer including (1) increased communication between patients, providers, and their communities [18]; (2) education of patients and caregivers; (3) integration of standard clinical assessments with PROs measured during routine 
clinical practice; (4) help of patients in monitoring their respective conditions [18]; (5) improved patient empowerment and self-management; and (6) improved evidence from clinical trials on the basis of PRO endpoints in studies evaluating anticancer treatments and prospective evaluations of supportive care interventions and real-world efficiency of care for cancer patients.

The objectives of the present review are to evaluate the state of digital health solutions in oncology supportive care allowing collection of ePRO and focused on symptom management and to identify benefits and limitations.

\section{Methods}

Guidance of the Preferred Reporting Items for Systematic Reviews and Meta-Analyses (PRISMA) statement was followed in the conduct of this study (Fig. 2).

\section{Search strategy}

The MEDLINE Public Library of Medicine (PubMed) database and the Cochrane Library were explored from December 1, 2008, to November 30, 2018, for relevant studies using the following search terms: (1) MEDLINE, "cancer or oncology" AND "telehealth or eHealth" AND "symptom management" or "symptom monitoring"; (2) Cochrane Library (title abstract keywords), "cancer or oncology" AND "telehealth or eHealth" AND "symptom". Clinicaltrials.gov search was performed using the following search strategy: "cancer or oncology" (condition or disease) AND "telehealth or eHealth" (other terms) AND "symptom" (outcomes measures).

\section{Study eligibility criteria (inclusion/exclusion)}

Screening of publication was done by 2 researchers on titles and abstracts and then full-text to ensure eligibility to the following criteria.
Fig. 2 PRISMA statement. PRISMA Preferred Reporting Items for Systematic Reviews and Meta-Analyses, RCT randomized controlled trial
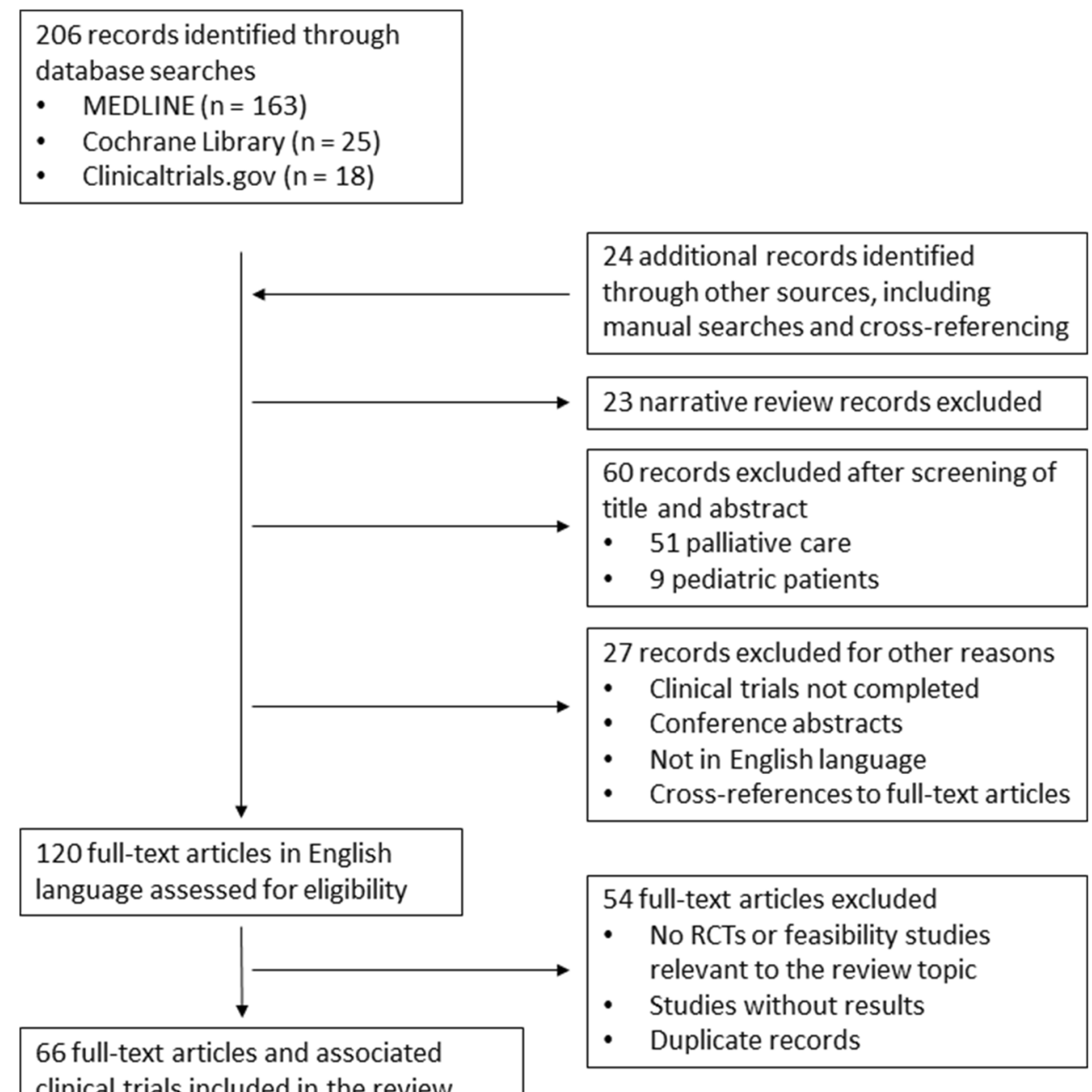
Inclusion criteria Adult cancer patients, all randomized controlled trials (RCTs) or feasibility and pilot studies that evaluated the effectiveness of telehealth or eHealth solutions in supportive cancer care were eligible for inclusion in English language.

Exclusion criteria Studies involving pediatric patients and those evaluating solutions at the palliative phase were excluded.

For results retrieved from clinicaltrials.gov, not completed studies or studies without published results were excluded.

Retrieved studies were reviewed, and those evaluating solutions at palliative latest phase of cancer were removed from the analysis.

\section{Outcomes of interest selected and assessed}

Outcomes of interest were as follows for each digital solution identified: description of the digital solution including PRO for supportive care in oncology, with remote monitoring, with/without patient automated symptoms self- management, its benefits, limitations, drivers of and barriers to adoption; unmet needs; PRO data including QOL outcomes; AE incidence, severity, and management; emergency room (ER) admissions and hospitalizations; health resource utilizations; and survival outcomes including OS.

\section{Data collection and analysis}

Search results were critically analyzed by the authors for relevance to the focus of this review. Two researchers extracted the data. The authors analyzed systematically according to outcomes of interests detailed above the study results to critically discuss the impact on outcomes of the various digital solutions.

\section{Results}

A total of 206 articles have been identified through databases searches in Medline, Cochrane, and Clinicaltrials.gov. Twenty-four (24) additional records were provided from other sources (manual search, cross-references). We excluded narrative reviews (23), publications which titles and abstracts were about pediatric population or focused on palliative care phase of cancer (60), and other records (27) (not completed results in clinical trials, conference abstracts, not in English language, cross references to full-text articles).

Regarding the 120 selected articles, another 54 full-text articles were excluded because of absence of study results, duplicates, or design (exclusion when not a RCT nor a feasibility study).
Finally, 66 full-text articles and associated clinical trials are included in this review.

\section{Digital health solutions in oncology}

The review results outlining the status of clinical evidence regarding digital health solutions that collect ePRO for supportive care in oncology are summarized in Table $1[7,8$, 25-86]. These 38 digital solutions can be classified into 2 main categories: the first, 17 digital solutions based on PRO collection only, and the second, 21 digital solutions providing also self-management. The key findings are summarized according to outcome.

\section{Clinical evidence for adoption of digital solutions}

Clinical evidence for digital health solutions evaluated in feasibility or randomized controlled studies are also summarized in Table 1 [7, 8, 25-86].

\section{Drivers and barriers to usage}

From the patient perspective, some of the key factors identified for the uptake of the digital tools included the following:

(1) Ease of use [30, 38, 44, 51, 53, 55, 64, 80];

(2) Reassurance [28, 30, 41, 48, 49, 55, 59, 70];

(3) High usability and usefulness [37, 42, 44, 58, 62, 74];

(4) Improved communication with HCPs [27, 29, 30, 53, 58] www.owise.uk;

(5) Correct generation of system alerts and fast response to alerts [28, 70, 80];

(6) Patient empowerment [29, 30, 69]; and

(7) The convenience of real-time reporting of symptoms [28, 37];

One study evaluating the extent of patient use of a Webbased intervention reported that reduction of cancer symptom distress was a key driver of uptake, with use of the intervention resulting in a significant reduction in distress score [47].

Conversely, some of the barriers for adoption encountered by patients were as follows:

(1) Problems with technology or connectivity [48, 49, 69, 80];

(2) Limited usefulness [29, 30, 71];

(3) Lack of clarity of the language used [29, 30]; and

(4) Generation of false alerts [69].

Whereas higher education level, current employment, and low levels of social support have been associated with uptake, lower education level and non-working status may be barriers to accessing interventions [47, 84]. 


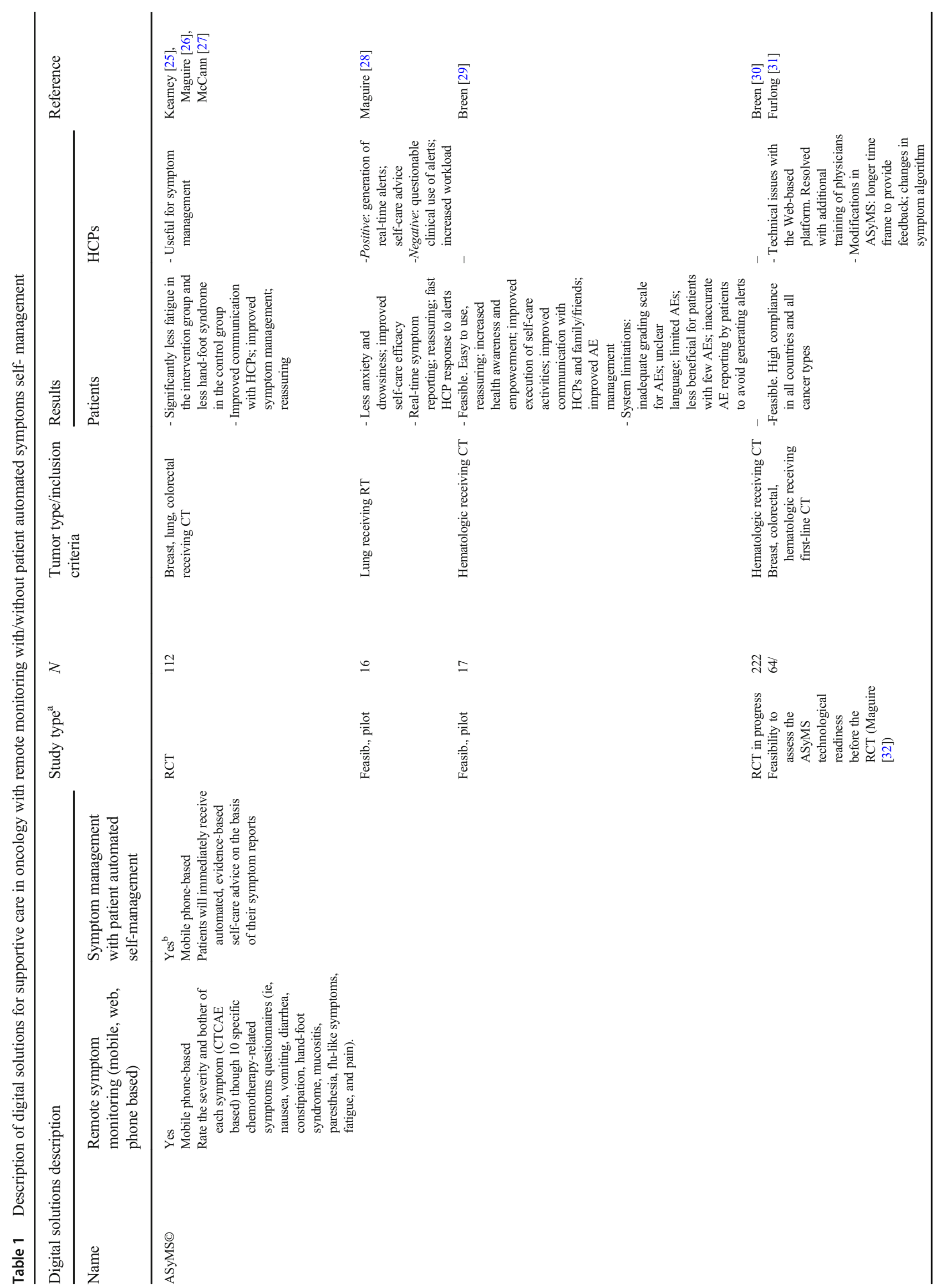




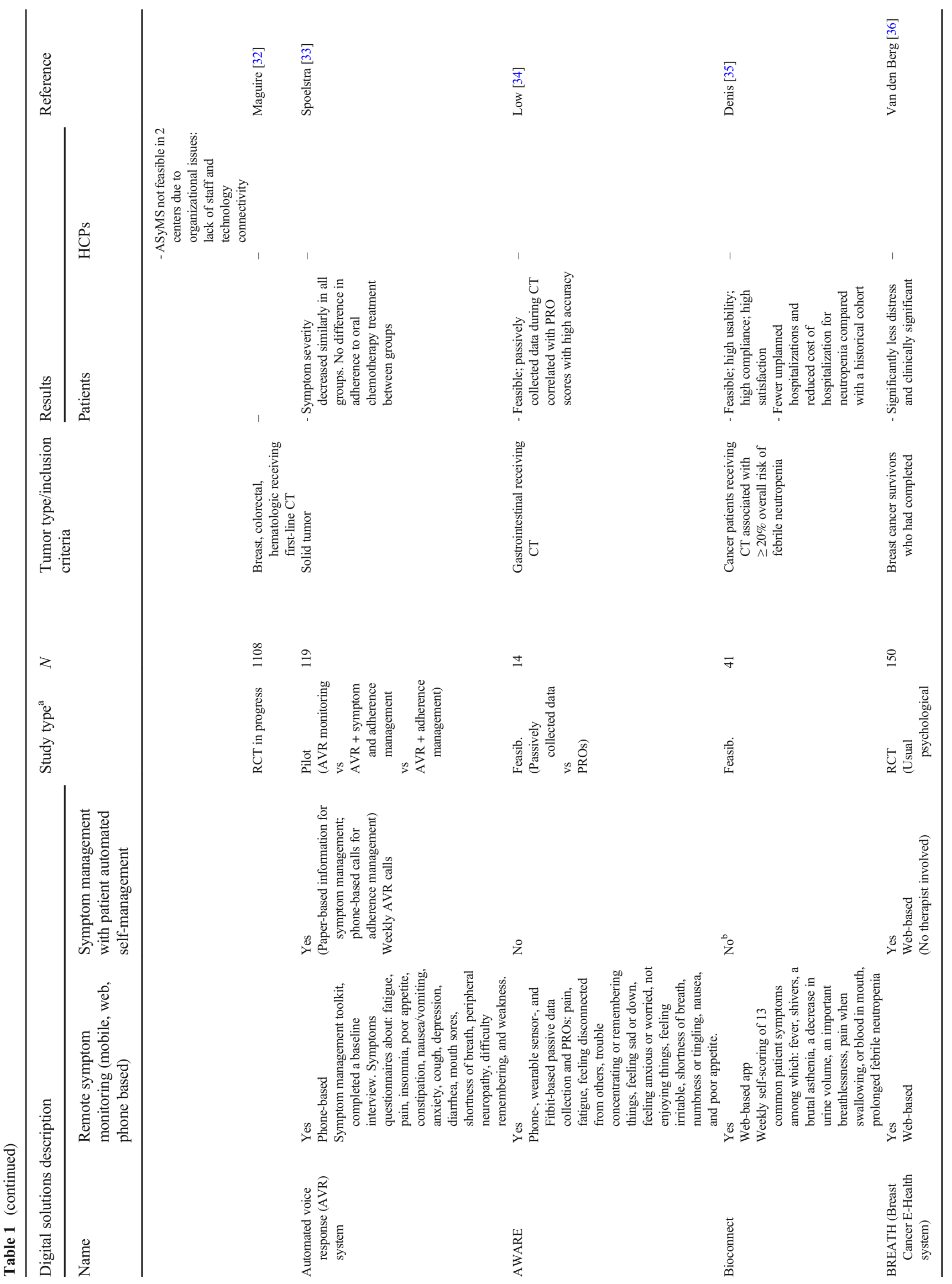




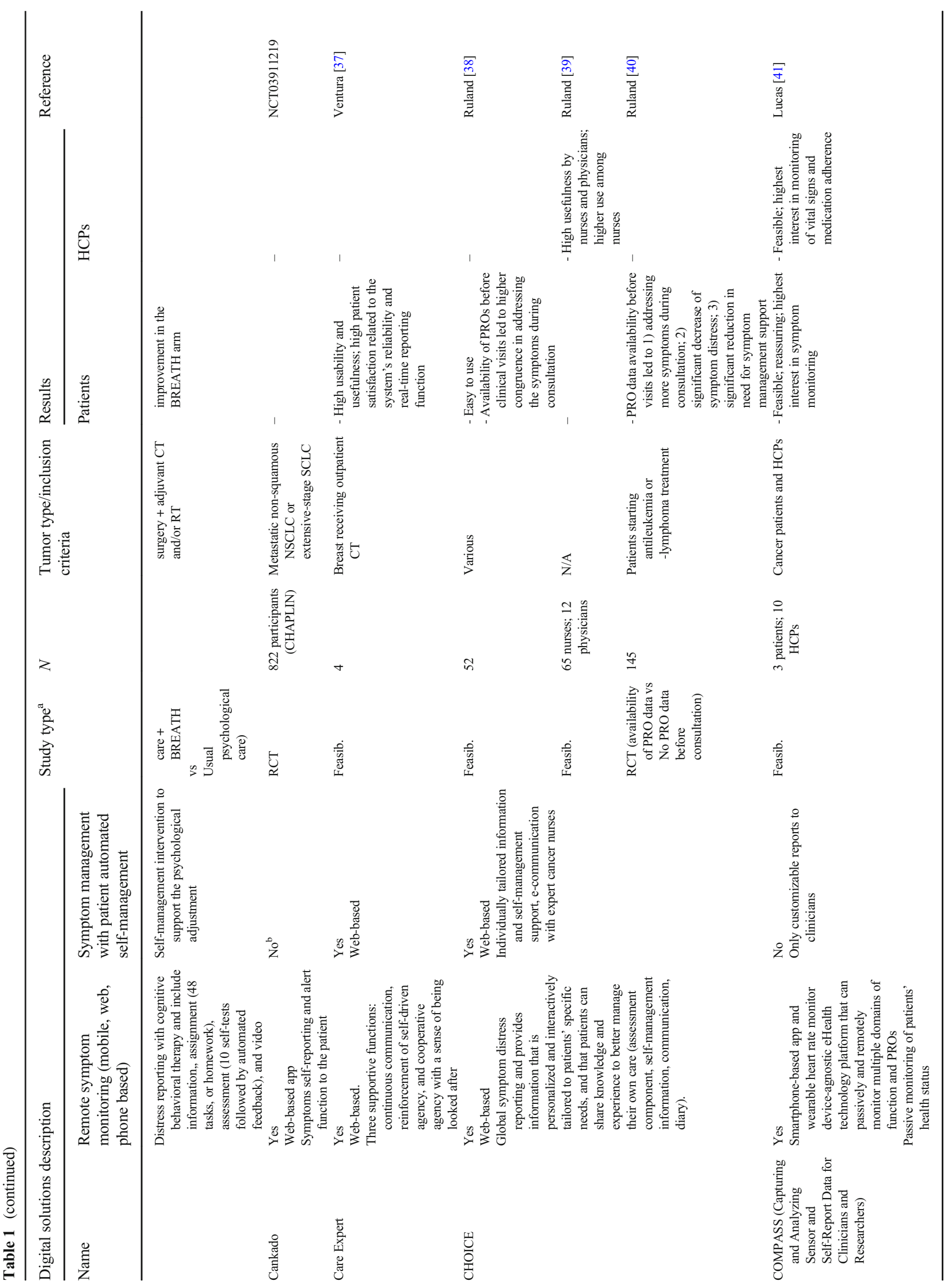




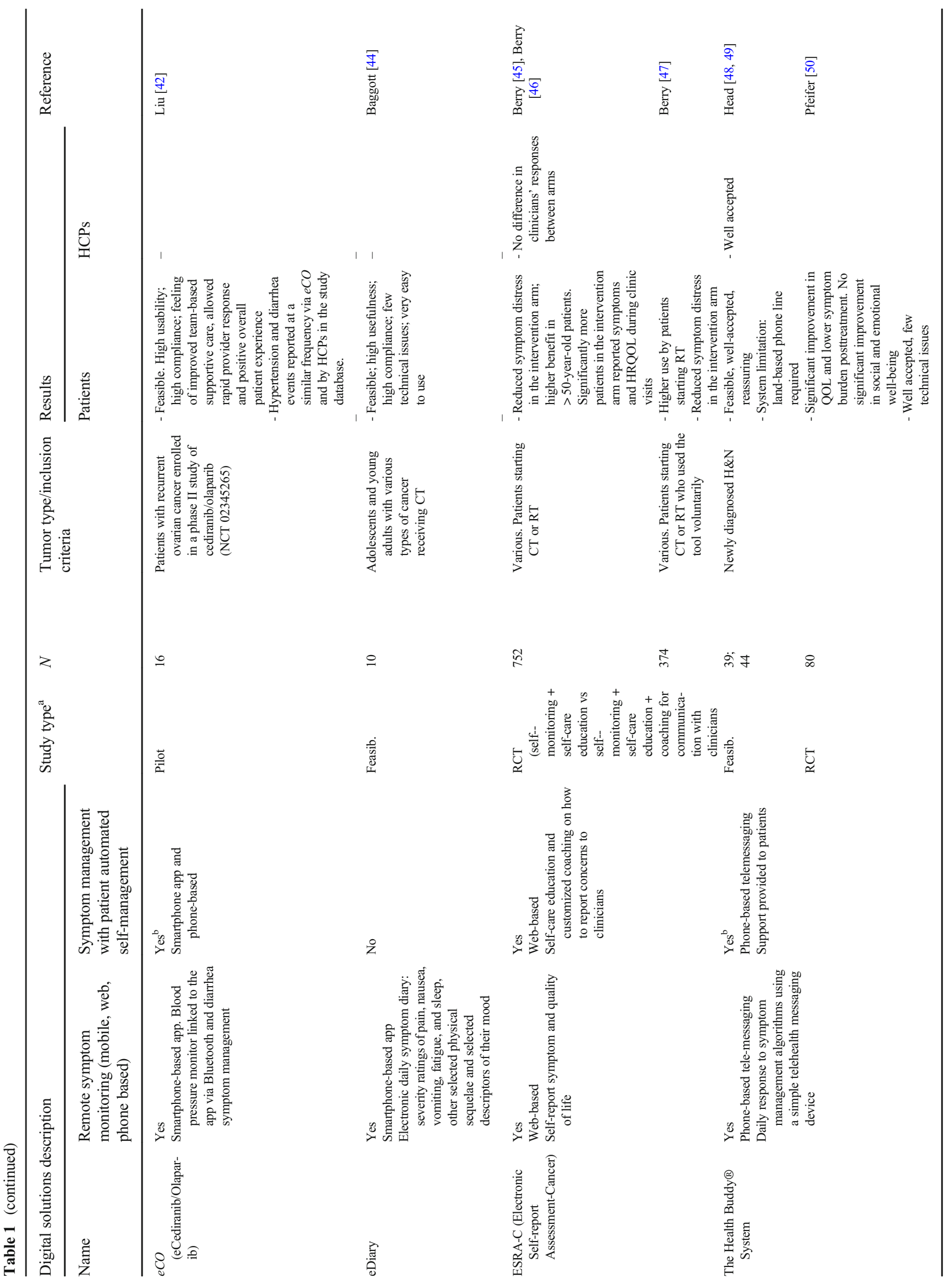




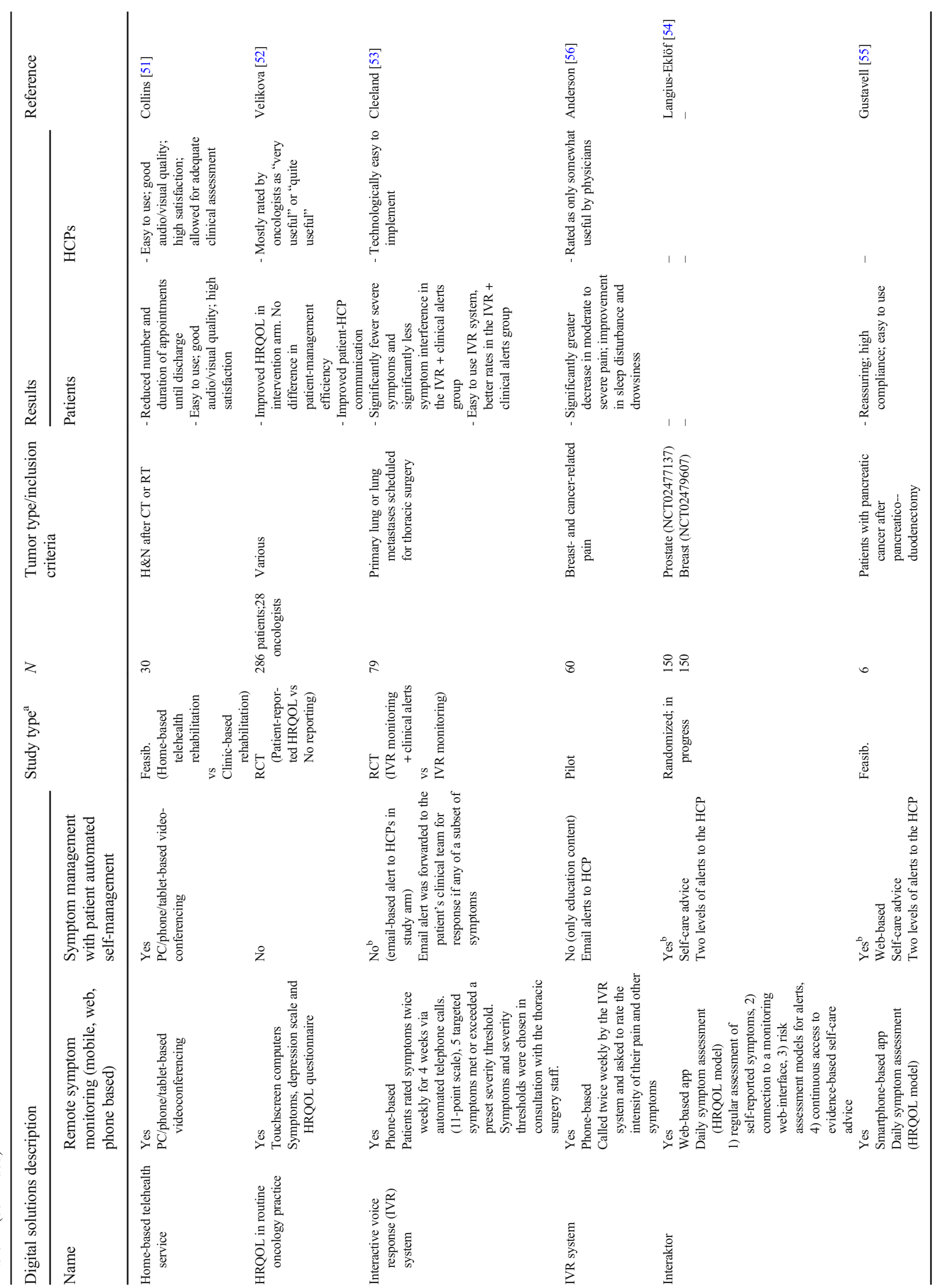




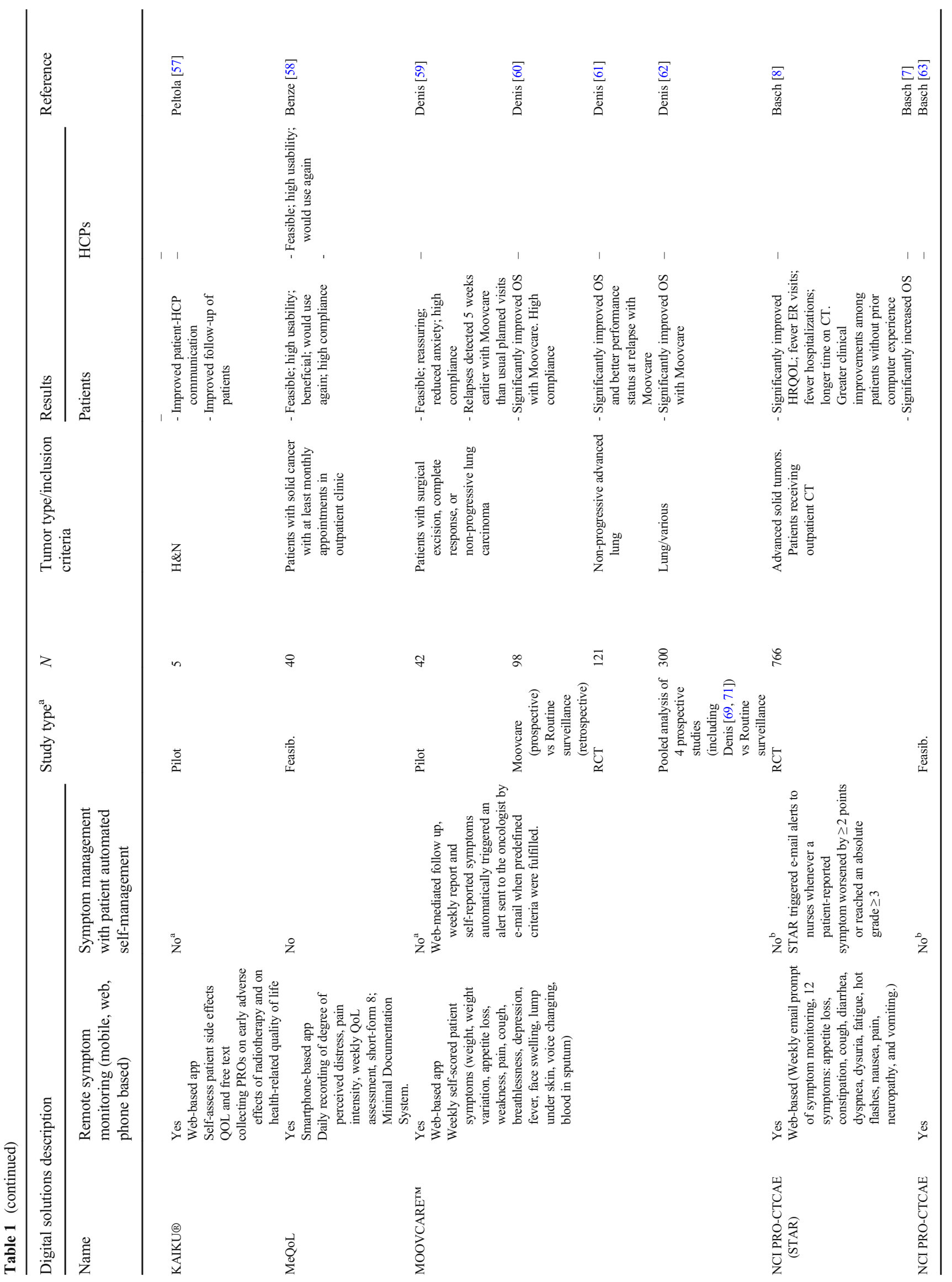




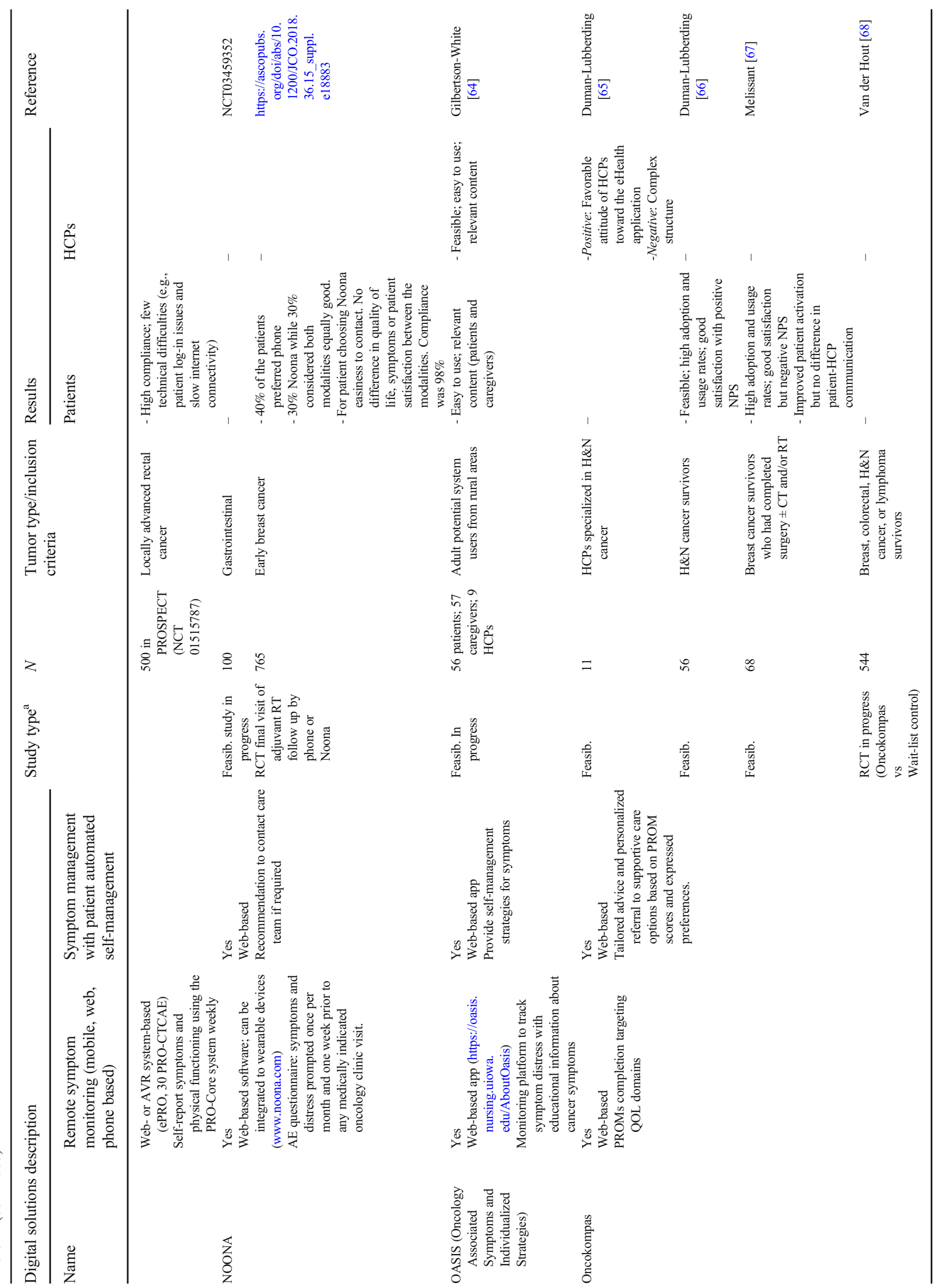




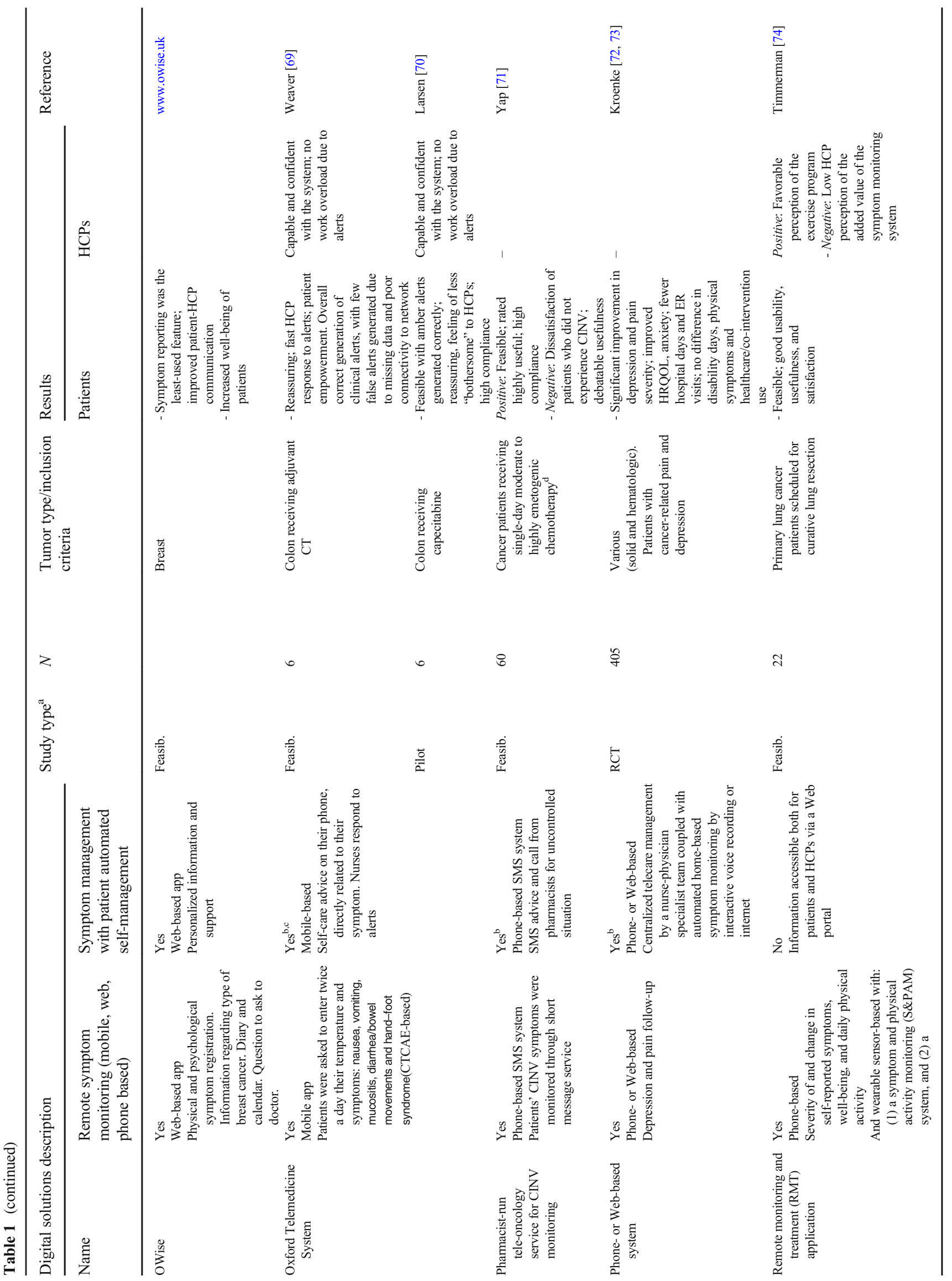




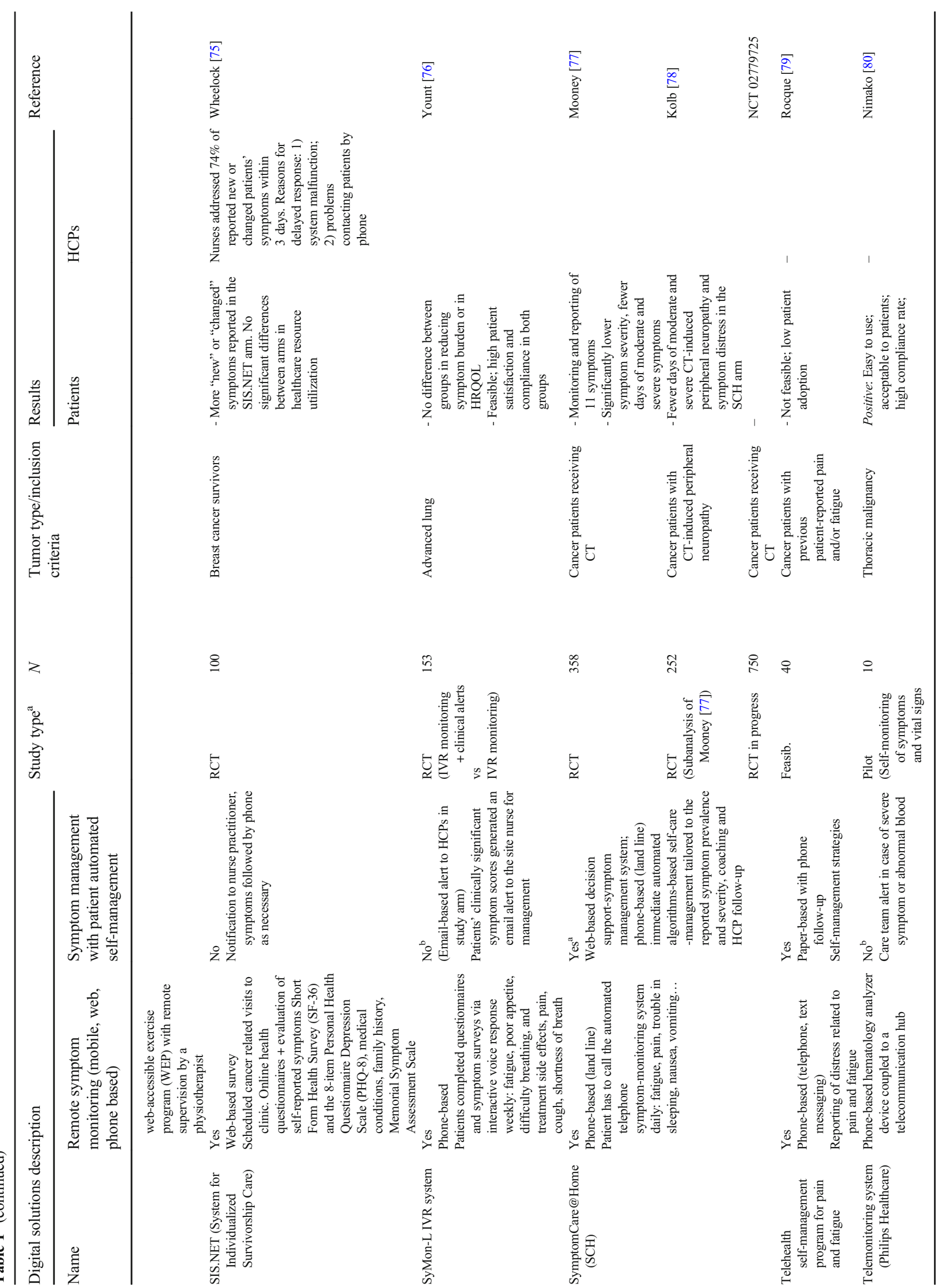




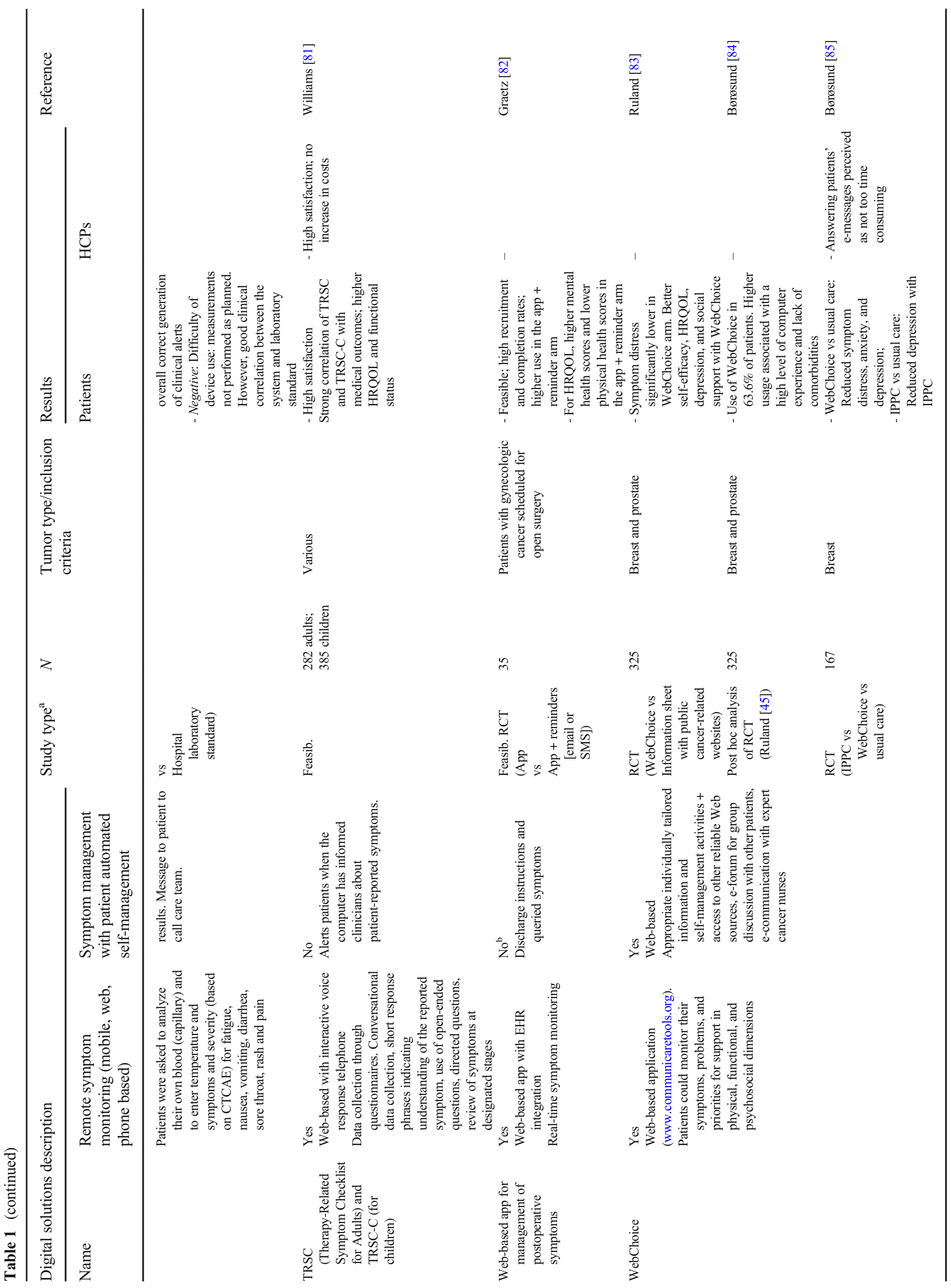




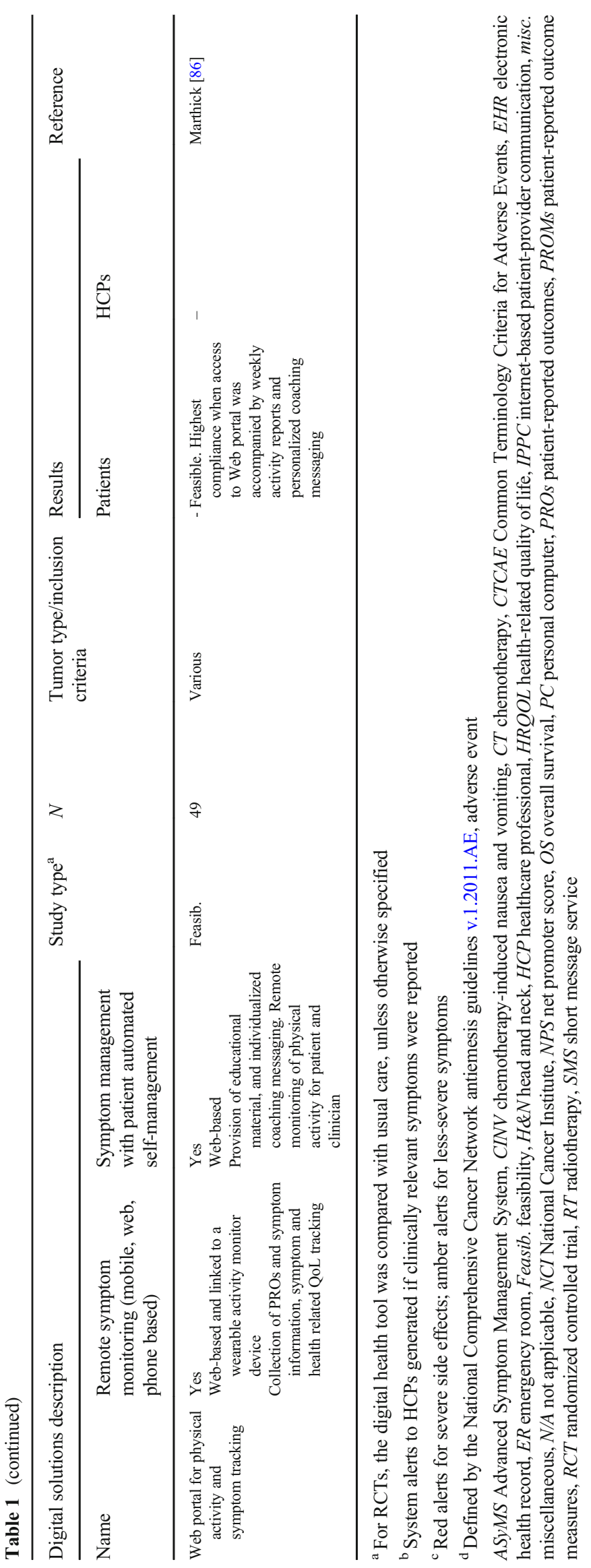


Fewer studies have assessed the feasibility of digital solutions from the HCP perspective. The most important reasons for adoption reported by HCPs were the usability and usefulness of the tool $[26,38,52,58]$, and the most commonly reported barrier was problems with technology or connectivity $[31,75]$.

Interestingly, while some tools were perceived as a burden due to increased workload [28], others did not impact the working time of HCPs $[69,85]$.

\section{Impact on clinical assessment}

Most studies presented ePRO data, including symptom distress and burden, pain, depression, and adherence.

A meta-analysis of 9 studies reported a statistically significant benefit for digital interventions in patients with cancerrelated fatigue, with moderate benefits also observed for QOL and depression [45].

Several studies showed a significant reduction compared with usual care in symptom-related distress on the basis of measures that included Short-Form (SF)-36, Memorial Symptom Assessment Scale (MSAS), Symptom Distress Scale-15 (SDS-15), and Functional Assessment of Cancer Therapy-Head \& Neck Scale (FACT-HN) [36, 40, 45, 47, $50,78,85]$. Symptom benefit was observed in conjunction with automated home or Web-based symptom self-management systems.

Studies also reported a reduction in depression [73, 85], symptom severity [33, 53], pain [43, 56, 73, 77], and need for symptom management support [40].

An RCT enrolling 766 patients with solid tumors receiving outpatient chemotherapy demonstrated that self-reporting of 12 common cancer-related symptoms led to significant improvement in QOL, as measured by the EuroQol EQ-5D Index [8].

Two studies used the European Organization for Research and Treatment of Cancer Qualify of Life Questionnaire Core 30 (EORTC-QLQ-C30) for QOL assessment [43, 52]. One of these used the EORTC-QLQ-C30 and the Hospital Anxiety and Depression Scale (HADS) as an intervention, with a larger proportion of patients who reported these measures to their oncologists showing clinically meaningful improvements in QOL compared with a control group, despite no detectable changes in patient management [52].

An RCT evaluating the impact of an internet-based exercise intervention reported significant improvement in EORTC-QLQ-C30 scores for global health status, physical, role, and cognitive functioning, together with improvements in pain severity on the Brief Pain Inventory compared with control [43].

In another study of a Web-based intervention, the addition of self-care instructions and communication coaching to Electronic Self-report Assessment-Cancer (ESRA-C) of symptoms and QOL resulted in significant increase in reporting fatigue, pain, and physical function issues. However, differences between groups in symptom distress reported by patient did not reach significance [46].

Finally, a report found benefit for patient QOL, including increased symptom identification and management, and improved functional status following electronic collection of Therapy-Related Symptom Checklist for Adults (TRSC) [81].

\section{Impact on survival}

A prospective study compared survival in patients with lung cancer who were assigned to weekly symptom self-reporting via a Web application intervention for early detection of relapse with a retrospective group of control patients [60]. Median OS was improved for the patients assigned to the intervention compared with the historical control arm.

Survival outcomes were also reported in 2 RCTs. A singlecenter trial reported that integration of ePROs into the routine care of patients with metastatic cancer led to increased survival compared with usual care [7]. At a median follow-up of 7 years, median OS was 31.2 months (95\% CI, 24.5-39.6) in the group that provided self-report of 12 common symptoms, with severe or worsening symptoms triggering an email alert and follow-up care by a nurse practitioner with escalation as needed. In comparison, median OS in the group assigned to usual care was 26.0 months (95\% CI, 22.1-30.9; difference, 5 months; $P=.03$ ). In patients with advanced lung cancer, a multicenter study reported that intervention involving a Webbased follow-up algorithm to assess weekly patient symptom self-reports compared with routine follow-up resulted in median OS of 19.0 (95\% CI, 12.5-noncalculable) and 12.0 months $(95 \% \mathrm{CI}, 8.6-16.4)$, respectively $(P=.001)$ [61]. In addition, the performance status at first relapse was 0 to 1 for $76 \%$ of patients in the intervention arm compared with $33 \%$ in the control arm $(2$-sided $P<.001)$; anticancer treatment was considered to be optimal in $72 \%$ and $33 \%$, respectively $(2$-sided $P<.001)$. In the final OS analysis for this study, median OS was 22.5 months in the intervention group and 14.9 months in the control group (hazard ratio, 0.59 [95\% CI, 0.37-0.96]; $P=.03$ ) [87].

\section{Impact on ER admissions, hospitalizations, and healthcare resource utilization}

The effect of digital solutions on the number of ER visits, hospital days, or utilization of healthcare resources is not commonly evaluated in clinical studies. Some solutions, involved in patient monitoring providing or not providing feedback for self-management, have been associated with a reduction in ER visits, unplanned hospitalizations, and hospital days [8, 35, 73]. Additionally, use of a telehealth system for rehabilitation of patients with head and neck cancer following chemo-/ 
radiotherapy resulted in fewer and shorter appointments until discharge compared with usual care and was accompanied by a significant cost-reduction for patients, specifically in travel costs [51]. On the contrary, one study using a Web-based intervention that included review by a nurse practitioner found no differences compared with control with respect to healthcare resource use, including oncology-related appointments, number of physician visits, or medical tests [75]. The effect of digital solutions on overall healthcare costs needs further assessment $[8,35,73,75]$.

\section{Clinical benefits and limitations of the digital solutions for stakeholders}

Benefits and limitations of introducing a patient-management solution in oncology, according to stakeholders of digital solutions in the healthcare system, are summarized in Table 2 and illustrated in Fig. 3. These benefits and limitations were identified in the selected publications and from the authors experience and opinion. Lots of benefits have been identified of important impact on all stakeholders (patients, physicians, caregivers, nurses, healthcare system, pharmaceutical company), with limitations related to technical dealing, regulatory constraints, costs, and changes in practices.

\section{Discussion}

Although the clinical benefits of remote patient monitoring have been demonstrated in clinical trials [7,62], achieving optimal supportive care requires strategies that go beyond ePRO apps/systems. Such benefits are not obtained solely

Table 2 Benefits and limitations of digital healthcare solutions for stakeholders

\begin{tabular}{|c|c|c|}
\hline Stakeholder & Benefits & Limitations \\
\hline Patients & $\begin{array}{l}\text { - Promote patient-centricity } \\
\text { - Direct communication with HCPs } \\
\text { - Closer involvement in the decision-making process } \\
\text { - Impact on treatment-adherence } \\
\text { - Information from clinical visits always available } \\
\text { - Relevant disease- and treatment-related information always available } \\
\text { - Less recourse to generic Web consultation without scientific content }\end{array}$ & $\begin{array}{l}\text { - Difficulty in dealing with technology } \\
\text { - Need for specific education and training } \\
\text { - Time-consuming } \\
\text { - Uncomfortable asking clinicians for } \\
\text { permission to record clinical visits } \\
\text { - Depersonalization }\end{array}$ \\
\hline Physicians & $\begin{array}{l}\text { - Improved communication with patients } \\
\text { - Shared decision-making by involving patients in the process } \\
\text { - Real-world data collection in real time } \\
\text { - Optimal management of toxicities in real time } \\
\text { - Increased motivation thanks to visible improvements } \\
\text { - Effective time-management } \\
\text { - Time saving in the analyses of patients' data } \\
\text { - Contact patients only when clinically relevant situations occur } \\
\text { - Focused supportive care } \\
\text { - Less healthcare resource utilization }\end{array}$ & $\begin{array}{l}\text { - Difficulty in dealing with technology } \\
\text { - Need for specific training to ensure engagement } \\
\text { - Time dedicated outside of consultation hours } \\
\text { - Changes in the organization of HCP teams } \\
\text { - Difficulty in changing usual practices of } \\
\text { symptom management }\end{array}$ \\
\hline Nurses & $\begin{array}{l}\text { - Effective time-management } \\
\text { - Time saving in the analyses of patients' data } \\
\text { - Contact patients only when clinically relevant situations occur } \\
\text { - Increased quality of services with less healthcare resource utilization } \\
\text { - Improved patient-nurse communication }\end{array}$ & $\begin{array}{l}\text { - Difficulty in dealing with technology } \\
\text { - Need for specific training to ensure engagement } \\
\text { - Time dedicated to educating and inform patients } \\
\text { and caregivers } \\
\text { - Additional time allocated outside patients' visits }\end{array}$ \\
\hline Caregivers & $\begin{array}{l}\text { - Reduced burden and anxiety } \\
\text { - Increased satisfaction }\end{array}$ & $\begin{array}{l}\text { - Difficulty in dealing with technology } \\
\text { - Need for specific education and training }\end{array}$ \\
\hline Healthcare system & $\begin{array}{l}\text { - Impact of preventive care in healthcare costs. Cost-effectiveness } \\
\text { benefits } \\
\text { - Reduction in ER visits, wait time in ER, transportation costs } \\
\text { - Reduction in unplanned visits and hospitalizations } \\
\text { - Impact on the working time of physicians, nurses, ER personnel } \\
\text { - Reduction in medication cost } \\
\text { - Prevention and treatment of AEs more consistent with guidelines }\end{array}$ & $\begin{array}{l}\text { - Need for development of processes and regulations } \\
\text { for homologation of digital solutions by regulatory } \\
\text { agencies } \\
\text { - Formation and training of dedicated teams for } \\
\text { evaluation } \\
\text { - Delays in cost-effectiveness analyses for the } \\
\text { implementation of reimbursement policies, } \\
\text { resulting } \\
\text { in impeded access to patients }\end{array}$ \\
\hline $\begin{array}{l}\text { Pharmaceutical } \\
\text { industry }\end{array}$ & $\begin{array}{l}\text { - Real-world data and increased knowledge of the toxicity profile of } \\
\text { drugs } \\
\text { - Development of plans for improved management of AEs } \\
\text { - Expedited approval of drugs when filing in combination with digital } \\
\text { solutions }\end{array}$ & $\begin{array}{l}\text { - Additional studies with the drug + digital solution } \\
\text { combination needs to be performed, to generate } \\
\text { clinical evidence of efficacy and safety to support } \\
\text { filing: increased time and cost }\end{array}$ \\
\hline
\end{tabular}

$A E$ adverse event, $E R$ emergency room, $H C P$ healthcare professional 
Fig. 3 Benefits and limitations of digital solutions in the healthcare system. FDA US Food and Drug Administration, HCP healthcare professional, IT information technology

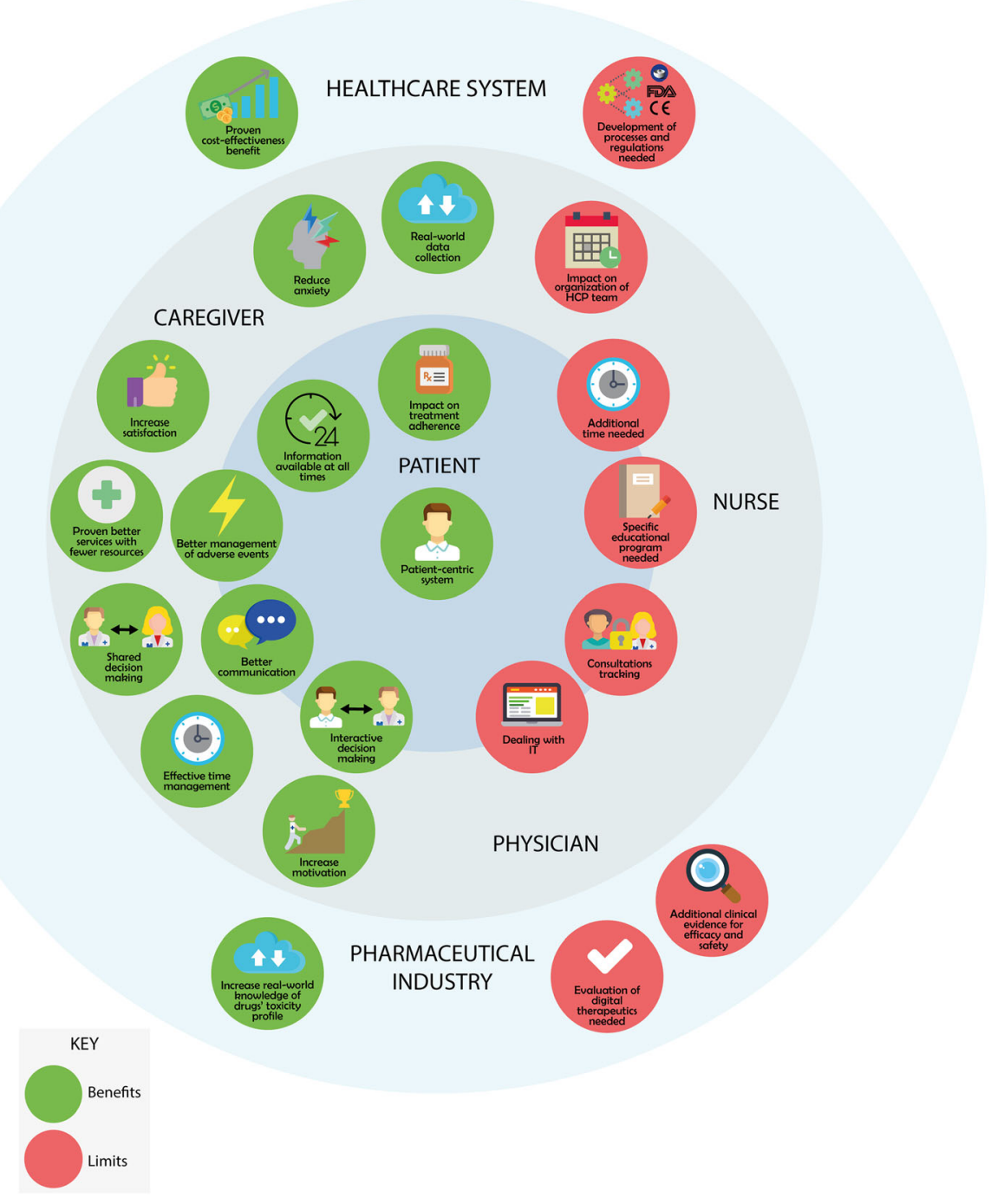

through the assessment of outcomes of interest but also through appropriate management in response to assessments. Even if benefits have been confirmed in the setting of RCTs, there is a need to continue to evaluate ePRO efficacy and efficiency in real-world conditions, with ongoing assurances of data security and privacy, to provide relevant information for optimal self-management.

Several factors need to be considered for a high-quality symptom self-management system. Guidance from the treating physician is critical. Electronic self-reported assessment tools for cancer-related symptoms and QOL can increase communication between patients and HCPs and promote discussion that is focused on symptoms and QOL. Digital tools that give advice to patients on the reporting of symptoms to HCPs have been shown to increase symptom reports by patients during visits. However, these have not been shown to impact practitioner responses, indicating that guideline adherence and commitment by the medical team is also needed. The collection of information regarding related clinical symptoms and the medication received requires integration with electronic real-time monitoring of symptoms into oncologists' routine clinical practice. When real-time monitoring is used, beneficial outcomes in terms of symptom management have been identified [88], with the potential for further optimization when structured patient education or practitioner-/nurse-led symptom counseling is in place. Optimization of digital tools requires integration with the patients' EHRs, thereby allowing continuity in the flow of patient-related data and the healthcare support systems.

Digital health solutions need to be integrated into the patient pathway and in healthcare team practices for optimal supportive care in oncology in line with appropriate guidelines. How this integration is implemented is debatable, with consideration given as to whether the digital tool is merged into current healthcare systems in a gradual or disruptive manner. The European Society for Medical Oncology (ESMO) has developed a Magnitude of Clinical Benefit Scale (ESMO-MCBS) to assess the extent of the clinical benefit from new and effective 


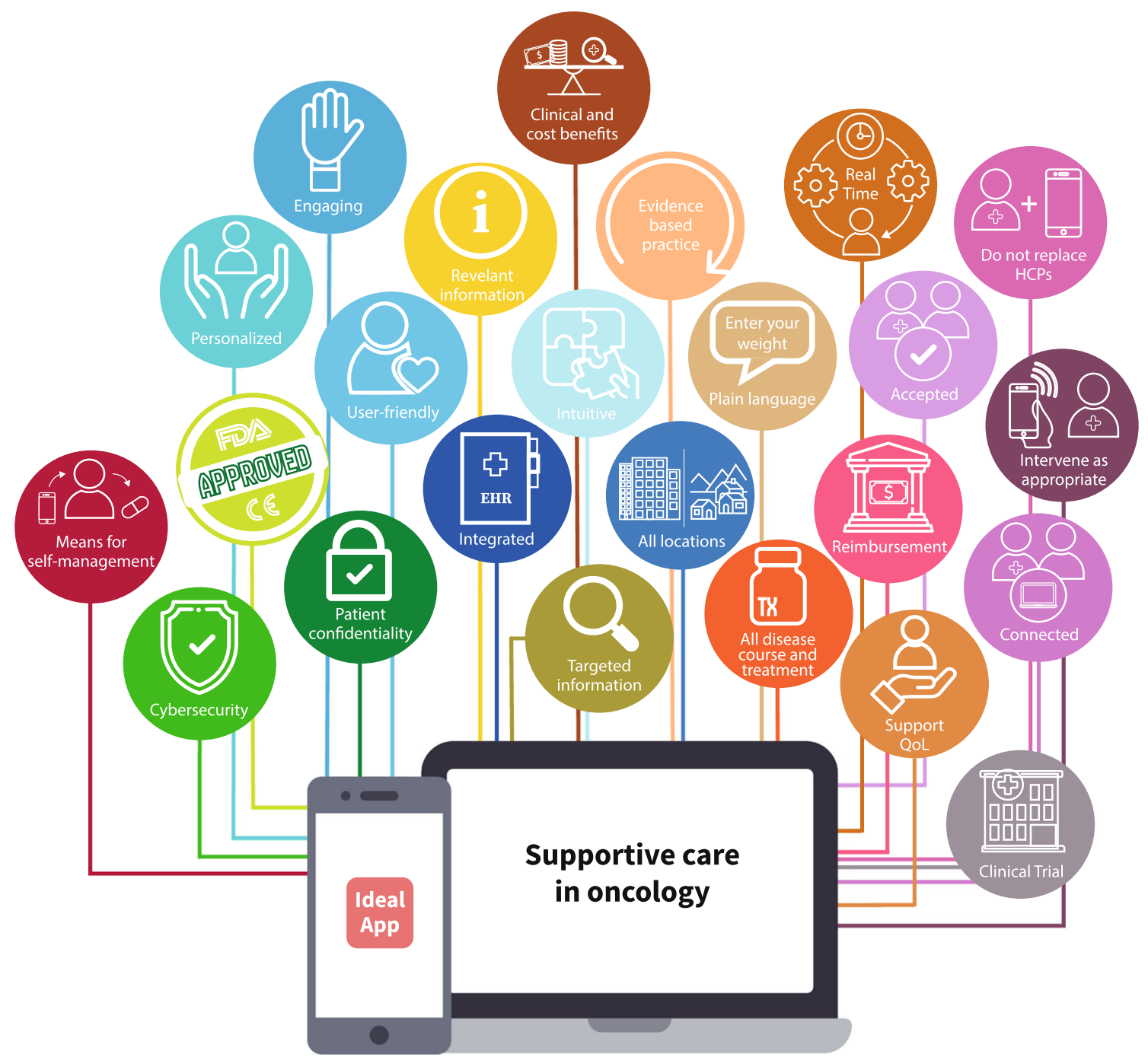

Fig. 4 Ideal digital health solution

anticancer therapies measuring improvement in survival, disease-free survival, response, grade 3-4 toxicities, and QOL measures [89]. MCBS-based assessment of the digital tools as part of anticancer therapies and the use of MCBS for the development of clinical guidelines would ease this integration.

There are challenges in the development of a digital solution for supportive care of cancer patients. Setting up and conducting clinical trials for the evaluation of digital tools is a long process, especially because digital solutions need to be quickly available for evaluation in real-world settings. The principal difficulties are in developing and implementing a solution to fit the needs of all or most patients, while achieving the necessary patient compliance to change with the new digital tool and integrate it into care and maintaining enough adaptability for its use in different regulatory systems and healthcare centers. Implementation may be associated with challenges in staff having to deal with new technologies, accepting and adapting to changes, and the potential for reorganization of multidisciplinary teams/treatment centers. Maintenance of the device may also introduce complexity since device utility is dependent on updates in accordance with relevant guidelines, as well as drug safety information, approval of new drugs, and the use of different drugs from the same class. Oncologic therapy is by its nature complex, with sequential phases, and device utility will need to reflect the use of different antitumor regimens, including radiotherapy and radio-chemotherapy, and combination of drugs. Uptake of the technology may be dependent on oncologist perceptions of patients' willingness to adopt new technologies, as well as the actual willingness of patient subgroups, particularly elderly patients, to embrace digital solutions. Finally, digital solutions should be perceived as facilitators of in-person communication between patient and practitioner.

This review offers elements for scoping digital solution based on feasibility studies on limited level of evidence or still limited numbers of patients evaluated on RCT. 


\section{Outlook for the future}

Several clinical studies have already demonstrated reliability, feasibility, and clinical value (various symptoms, QOL, and OS) with efficacy of ePRO collection through digital solutions. The ideal digital solution in the setting of supportive care in oncology would present with the following characteristics (Fig. 4): it would be user-friendly, intuitive, and engaging to meet the immediate needs of the end-users; it would also be efficient at processing and delivering relevant information to provide supportive care as its principal aim. In thinking about its place in the supportive care setting, the ideal digital solution is not intended as a replacement for the practitioner; rather, its intended value would be in providing additional information that is appropriate to the care of the patient and the specific issues associated with their disease in real time. This information would be sufficiently detailed but not overcomplicated and presented in a language the patient understands in order to be accessible by the patient for effective symptom self-management [90]. The digital solution would maintain existing expectations regarding patient confidentiality and data privacy [91], cybersecurity, compliance with regulatory requirements, and being updated according to the most recent evidence-based practice. It would be operational throughout the entire course of the disease and for all anticancer treatments. Its built-in flexibility would enable adaptation of the digital tool to all territories, institutions, and centers and to all different care needs according to whether treatment is delivered in the community or at a regional center, such that it also serves patients who live in remote areas. It would be customizable to adapt to the needs of the individual patient. It would have a seamless connection with HCPs' systems. Integration with patients' EHR would allow for rapid follow-up and intervention as appropriate by HCPs in response to system alerts triggered by patient reports of clinically relevant events. It would have a high level of acceptance both by HCPs and patients, allowing its complete adoption and full integration in the patient pathway and in routine clinical practice. For digital solutions with proven clinical and cost benefits, reimbursement policies would be in place to ensure availability for implementation through defined market access programs. Finally, the ideal digital solution would not only provide the means for patient self-management of anticancer treatment-related symptoms but would also provide psychosocial support and improve QOL. Although a single system would not be able to address all needs - treatment adherence, symptom management, alignment with guidelines, medication reminders, medical and nutritional information, resources for social support, and coping strategies-it is important that digital tools find common ground, with solutions offered to address key challenges in the setting of supportive care in cancer.
Acknowledgments Editorial and medical writing assistance was provided by Iratxe Abarrategui, PhD, CMPP, Aptitude Health, The Hague, The Netherlands, and Howard Christian, PhD, Mediscinz Communications Limited. The authors are responsible for all content and editorial decisions for this manuscript.

Funding information This work was supported by funding from Voluntis S.A., Suresnes, France.

\section{Compliance with ethical standards}

The authors have a medical expertise contract with Voluntis. However, they do not receive any specific remuneration in consideration of this publication.

Open Access This article is licensed under a Creative Commons Attribution 4.0 International License, which permits use, sharing, adaptation, distribution and reproduction in any medium or format, as long as you give appropriate credit to the original author(s) and the source, provide a link to the Creative Commons licence, and indicate if changes were made. The images or other third party material in this article are included in the article's Creative Commons licence, unless indicated otherwise in a credit line to the material. If material is not included in the article's Creative Commons licence and your intended use is not permitted by statutory regulation or exceeds the permitted use, you will need to obtain permission directly from the copyright holder. To view a copy of this licence, visit http://creativecommons.org/licenses/by/4.0/.

\section{References}

1. Ferlay J, Colombet M, Soerjomataram I, Mathers C, Parkin DM, Piñeros M, Znaor A, Bray F (2019) Estimating the global cancer incidence and mortality in 2018: GLOBOCAN sources and methods. Int J Cancer 144:1941-1953

2. Allemani C, Matsuda T, Di Carlo V et al (2018) Global surveillance of trends in cancer survival 2000-14 (CONCORD-3): analysis of individual records for 37513025 patients diagnosed with one of 18 cancers from 322 population-based registries in 71 countries. Lancet 391:1023-1075

3. Ferlay J, Soerjomataram I, Dikshit R, Eser S, Mathers C, Rebelo M, Parkin DM, Forman D, Bray F (2015) Cancer incidence and mortality worldwide: sources, methods and major patterns in GLOBOCAN 2012. Int J Cancer 136:E359-E386

4. Cook R (2008) Economic and clinical impact of multiple myeloma to managed care. J Manag Care Pharm 14:19-25

5. Jordan K, Aapro M, Kaasa S, Ripamonti CI, Scotté F, Strasser F, Young A, Bruera E, Herrstedt J, Keefe D, Laird B, Walsh D, Douillard JY, Cervantes A (2018) European Society for Medical Oncology (ESMO) position paper on supportive and palliative care. Ann Oncol 29:36-43

6. Kaasa S, Loge JH, Aapro M, Albreht T, Anderson R, Bruera E, Brunelli C, Caraceni A, Cervantes A, Currow DC, Deliens L, Fallon M, Gómez-Batiste X, Grotmol KS, Hannon B, Haugen DF, Higginson IJ, Hjermstad MJ, Hui D, Jordan K, Kurita GP, Larkin PJ, Miccinesi G, Nauck F, Pribakovic R, Rodin G, Sjøgren P, Stone P, Zimmermann C, Lundeby T (2018) Integration of oncology and palliative care: a Lancet Oncology Commission. Lancet Oncol 19:e588-e653

7. Basch E, Deal AM, Dueck AC, Scher HI, Kris MG, Hudis C, Schrag D (2017) Overall survival results of a trial assessing patient-reported outcomes for symptom monitoring during routine cancer treatment. JAMA 318:197-198 
8. Basch E, Deal AM, Kris MG, Scher HI, Hudis CA, Sabbatini P, Rogak L, Bennett AV, Dueck AC, Atkinson TM, Chou JF, Dulko D, Sit L, Barz A, Novotny P, Fruscione M, Sloan JA, Schrag D (2016) Symptom monitoring with patient-reported outcomes during routine cancer treatment: a randomized controlled trial. J Clin Oncol 34:557-565

9. Beaton L, Bandula S, Gaze MN, Sharma RA (2019) How rapid advances in imaging are defining the future of precision radiation oncology. Br J Cancer 120:779-790

10. Kaufman HL, Atkins MB, Subedi P, Wu J, Chambers J, Joseph Mattingly T, Campbell JD, Allen J, Ferris AE, Schilsky RL, Danielson D, Lichtenfeld JL, House L, Selig WKD (2019) The promise of immuno-oncology: implications for defining the value of cancer treatment. J Immunother Cancer 7:129

11. Galligioni E, Piras EM, Galvagni M, Eccher C, Caramatti S, Zanolli D, Santi J, Berloffa F, Dianti M, Maines F, Sannicolò M, Sandri M, Bragantini L, Ferro A, Forti S (2015) Integrating mHealth in oncology: experience in the province of Trento. J Med Internet Res 17: e114

12. Shah CP, Moreb JS (2019) Cardiotoxicity due to targeted anticancer agents: a growing challenge. Ther Adv Cardiovasc Dis 13: 1753944719843435

13. McCarthy PL, Holstein SA, Petrucci MT et al (2017) Lenalidomide maintenance after autologous stem-cell transplantation in newly diagnosed multiple myeloma: a meta-analysis. J Clin Oncol 35: 3279-3289

14. Partridge AH, Wang PS, Winer EP, Avorn J (2003) Nonadherence to adjuvant tamoxifen therapy in women with primary breast cancer. J Clin Oncol 21:602-606

15. Barquín-García A, Molina-Cerrillo J, Garrido P, Garcia-Palos D, Carrato A, Alonso-Gordoa T (2019) New oncologic emergencies: what is there to know about immunotherapy and its potential side effects? Eur J Intern Med 66:1-8

16. American Society of Clinical Oncology. The state of cancer care in America, 2016: a report by the American Society of Clinical Oncology. 2016. https://doi.org/10.1200/jop.2015.010462. Accessed September 24, 2019

17. Meskó B, Drobni Z, Bényei É, Gergely B, Győrffy Z (2017) Digital health is a cultural transformation of traditional healthcare. Mhealth 3:38

18. Kruse CS, Goswamy R, Raval Y, Marawi S (2016) Challenges and opportunities of big data in health care: a systematic review. JMIR Med Inform 4:e38

19. Schneeweiss S, Eichler HG, Garcia-Altes A, Chinn C, Eggimann AV, Garner S, Goettsch W, Lim R, Löbker W, Martin D, Müller T, Park BJ, Platt R, Priddy S, Ruhl M, Spooner A, Vannieuwenhuyse B, Willke RJ (2016) Real-world data in adaptive biomedical innovation: a framework for generating evidence fit for decision-making. Clin Pharmacol Ther 100:633-646

20. van Roessel I, Reumann M, Brand A (2017) Potentials and challenges of the health data cooperative model. Public Health Genomics 20:321-331

21. Raposo VL. Telemedicine: the legal framework (or the lack of it) in Europe. GMS Health Technol Assess 2016; 12: Doc03

22. Rajkomar A, Dean J, Kohane I (2019) Machine learning in medicine. N Engl J Med 380:1347-1358

23. Fallowfield LJ (2018) Quality of life assessment using patient-reported outcome (PRO) measures: still a Cinderella outcome? Ann Oncol 29:2286-2287

24. Aapro M, Molassiotis A, Dicato M, Peláez I, Rodríguez-Lescure Á, Pastorelli D, Ma L, Burke T, Gu A, Gascon P, Roila F, PEER investigators (2012) The effect of guideline-consistent antiemetic therapy on chemotherapy-induced nausea and vomiting (CINV): the Pan European Emesis registry (PEER). Ann Oncol 23:19861992
25. Kearney N, McCann L, Norrie J et al (2009) Evaluation of a mobile phone-based, advanced symptom management system (ASyMS) in the management of chemotherapy-related toxicity. Support Care Cancer 17:437444

26. Maguire R, McCann L, Miller M, Kearney N (2008) Nurse's perceptions and experiences of using a mobile-phone-based Advanced Symptom Management System (ASyMS) to monitor and manage chemotherapy-related toxicity. Eur J Oncol Nurs 12:380-386

27. McCann L, Maguire R, Miller M, Kearney N (2009) Patients' perceptions and experiences of using a mobile phone-based advanced symptom management system (ASyMS) to monitor and manage chemotherapy related toxicity. Eur J Cancer Care (Engl) 18:156164

28. Maguire R, Ream E, Richardson A, Connaghan J, Johnston B, Kotronoulas G, Pedersen V, McPhelim J, Pattison N, Smith A, Webster L, Taylor A, Kearney N (2015) Development of a novel remote patient monitoring system: the advanced symptom management system for radiotherapy to improve the symptom experience of patients with lung cancer receiving radiotherapy. Cancer Nurs 38:E37-E47

29. Breen S, Kofoed S, Ritchie D, Dryden T, Maguire R, Kearney N, Aranda S (2017) Remote real-time monitoring for chemotherapy side-effects in patients with blood cancers. Collegian 24:541-549

30. Breen S, Ritchie D, Schofield P et al (2015) The Patient Remote Intervention and Symptom Management System (PRISMS) - a Telehealth-mediated intervention enabling real-time monitoring of chemotherapy side-effects in patients with haematological malignancies: study protocol for a randomised controlled trial. Trials 16 : 472

31. Furlong E, Darley A, Fox P, Buick A, Kotronoulas G, Miller M, Flowerday A, Miaskowski C, Patiraki E, Katsaragakis S, Ream E, Armes J, Gaiger A, Berg G, McCrone P, Donnan P, McCann L, Maguire R (2019) Adaptation and implementation of a mobile phone-based remote symptom monitoring system for people with cancer in Europe. JMIR Cancer 5:e10813

32. Maguire R, Fox PA, McCann L, Miaskowski C, Kotronoulas G, Miller M, Furlong E, Ream E, Armes J, Patiraki E, Gaiger A, Berg GV, Flowerday A, Donnan P, McCrone P, Apostolidis K, Harris J, Katsaragakis S, Buick AR, Kearney N (2017) The eSMART study protocol: a randomised controlled trial to evaluate electronic symptom management using the advanced symptom management system (ASyMS) remote technology for patients with cancer. BMJ Open 7:e015016

33. Spoelstra SL, Given BA, Given CW, Grant M, Sikorskii A, You M, Decker V (2013) An intervention to improve adherence and management of symptoms for patients prescribed oral chemotherapy agents: an exploratory study. Cancer Nurs 36:18-28

34. Low CA, Dey AK, Ferreira D, Kamarck T, Sun W, Bae S, Doryab A (2017) Estimation of symptom severity during chemotherapy from passively sensed data: exploratory study. J Med Internet Res 19:e420

35. Denis F, Voog E, Pointreau Y, Bourgeois H, Seegers V, le du K (2019) Prospective study of a web-mediated management of febrile neutropenia related to chemotherapy (Bioconnect). Support Care Cancer 27:2189-2194

36. van den Berg SW, Gielissen MF, Custers JA et al (2015) BREATH: web-based self-management for psychological adjustment after primary breast cancer-results of a multicenter randomized controlled trial. J Clin Oncol 33:2763-2771

37. Ventura F, Koinberg I, Sawatzky R, Karlsson P, Öhlén J (2016) Exploring the person-centeredness of an innovative e-supportive system aimed at person-centered care: prototype evaluation of the care expert. Comput Inform Nurs 34:231-239

38. Ruland CM, White T, Stevens M, Fanciullo G, Khilani SM (2003) Effects of a computerized system to support shared decision making 
in symptom management of cancer patients: preliminary results. J Am Med Inform Assoc 10:573-579

39. Ruland CM (2006) Clinicians' perceived usefulness of a support system for patient-centered cancer care. Stud Health Technol Inform 124:624-630

40. Ruland CM, Holte HH, Røislien J et al (2010) Effects of a computer-supported interactive tailored patient assessment tool on patient care, symptom distress, and patients' need for symptom management support: a randomized clinical trial. J Am Med Inform Assoc 17:403-410

41. Lucas AR, Bass MB, Rothrock NE, O'Connor ML, Sorkin MR, Nawyn J, Albinali F, Wagner LI (2018) Development of an eHealth system to capture and analyze patient sensor and self-report data: mixed-methods assessment of potential applications to improve cancer care delivery. JMIR Med Inform 6:e46

42. Liu JF, Lee JM, Strock E, Phillips R, Mari K, Killiam B, Bonam M, Milenkova T, Kohn EC, Ivy SP (2018) Technology applications: use of digital health technology to enable drug development. JCO Clin Cancer Inform 2:1-12

43. Galiano-Castillo N, Cantarero-Villanueva I, Fernández-Lao C, Ariza-García A, Díaz-Rodríguez L, del-Moral-Ávila R, ArroyoMorales M (2016) Telehealth system: a randomized controlled trial evaluating the impact of an internet-based exercise intervention on quality of life, pain, muscle strength, and fatigue in breast cancer survivors. Cancer 122:3166-3174

44. Baggott C, Gibson F, Coll B, Kletter R, Zeltzer P, Miaskowski C (2012) Initial evaluation of an electronic symptom diary for adolescents with cancer. JMIR Res Protoc 1:e23

45. Berry DL, Hong F, Halpenny B, Partridge AH, Fann JR, Wolpin S, Lober WB, Bush NE, Parvathaneni U, Back AL, Amtmann D, Ford R (2014) Electronic self-report assessment for cancer and self-care support: results of a multicenter randomized trial. J Clin Oncol 32: 199-205

46. Berry DL, Hong F, Halpenny B, Partridge A, Fox E, Fann JR, Wolpin S, Lober WB, Bush N, Parvathaneni U, Amtmann D, Ford R (2014) The electronic self-report assessment and intervention for cancer: promoting patient verbal reporting of symptom and quality of life issues in a randomized controlled trial. BMC Cancer $14: 513$

47. Berry DL, Blonquist TM, Patel RA et al (2015) Exposure to a patient-centered, Web-based intervention for managing cancer symptom and quality of life issues: impact on symptom distress. J Med Internet Res 17:e136

48. Head BA, Studts JL, Bumpous JM, Gregg JL, Wilson L, Keeney C, Scharfenberger JA, Pfeifer MP (2009) Development of a telehealth intervention for head and neck cancer patients. Telemed J E Health $15: 44-52$

49. Head BA, Keeney C, Studts JL, Khayat M, Bumpous J, Pfeifer M (2011) Feasibility and acceptance of a telehealth intervention to promote symptom management during treatment for head and neck cancer. J Support Oncol 9:e1-e11

50. Pfeifer MP, Keeney C, Bumpous J, Schapmire T, Studts J, Myers J, Head B (2015) Impact of a telehealth intervention on quality of life and symptom distress in patients with head and neck cancer. $\mathrm{J}$ Community Support Oncol 13:14-21

51. Collins A, Burns CL, Ward EC, Comans T, Blake C, Kenny L, Greenup P, Best D (2017) Home-based telehealth service for swallowing and nutritional management following head and neck cancer treatment. J Telemed Telecare 23:866-872

52. Velikova G, Booth L, Smith AB, Brown PM, Lynch P, Brown JM, Selby PJ (2004) Measuring quality of life in routine oncology practice improves communication and patient well-being: a randomized controlled trial. J Clin Oncol 22:714-724

53. Cleeland CS, Wang XS, Shi Q, Mendoza TR, Wright SL, Berry MD, Malveaux D, Shah PK, Gning I, Hofstetter WL, Putnam JB Jr, Vaporciyan AA (2011) Automated symptom alerts reduce postoperative symptom severity after cancer surgery: a randomized controlled clinical trial. J Clin Oncol 29:994-1000

54. Langius-Eklöf A, Crafoord MT, Christiansen M, Fjell M, Sundberg $\mathrm{K}$ (2017) Effects of an interactive mHealth innovation for early detection of patient-reported symptom distress with focus on participatory care: protocol for a study based on prospective, randomised, controlled trials in patients with prostate and breast cancer. BMC Cancer 17:466

55. Gustavell T, Langius-Eklöf A, Wengström Y, Segersvärd R, Sundberg K (2019) Development and feasibility of an interactive smartphone app for early assessment and management of symptoms following pancreaticoduodenectomy. Cancer Nurs 42:E1E10

56. Anderson KO, Palos GR, Mendoza TR, Cleeland CS, Liao KP, Fisch MJ, Garcia-Gonzalez A, Rieber AG, Nazario LA, Valero V, Hahn KM, Person CL, Payne R (2015) Automated pain intervention for underserved minority women with breast cancer. Cancer 121:1882-1890

57. Peltola MK, Lehikoinen JS, Sippola LT et al (2016) A novel digital patient-reported outcome platform for head and neck oncology patients-a pilot study. Clin Med Insights Ear Nose Throat 9:1-6

58. Benze G, Nauck F, Alt-Epping B, Gianni G, Bauknecht T, Ettl J, Munte A, Kretzschmar L, Gaertner J (2019) PROutine: a feasibility study assessing surveillance of electronic patient reported outcomes and adherence via smartphone app in advanced cancer. Ann Palliat Med 8:104-111

59. Denis F, Viger L, Charron A, Voog E, Dupuis O, Pointreau Y, Letellier C (2014) Detection of lung cancer relapse using self-reported symptoms transmitted via an internet web-application: pilot study of the sentinel follow-up. Support Care Cancer 22:14671473

60. Denis F, Yossi S, Septans AL, Charron A, Voog E, Dupuis O, Ganem G, Pointreau Y, Letellier C (2017) Improving survival in patients treated for a lung cancer using self-evaluated symptoms reported through a web application. Am J Clin Oncol 40:464-469

61. Denis F, Lethrosne C, Pourel N, Molinier O, Pointreau Y, Domont $\mathrm{J}$, Bourgeois $\mathrm{H}$, Senellart $\mathrm{H}$, Trémolières $\mathrm{P}$, Lizée $\mathrm{T}$, Bennouna $\mathrm{J}$, Urban T, el Khouri C, Charron A, Septans AL, Balavoine M, Landry S, Solal-Céligny P, Letellier C (2017) Randomized trial comparing a web-mediated follow-up with routine surveillance in lung cancer patients. J Natl Cancer Inst 109

62. Denis F, Basch EM, Lethrosne C et al (2018) Randomized trial comparing a web-mediated follow-up via patient-reported outcomes (PRO) vs. routine surveillance in lung cancer patients: final results. J Clin Oncol 36:abstract 6500

63. Basch E, Dueck AC, Rogak LJ et al (2018) Feasibility of implementing the patient-reported outcomes version of the Common Terminology Criteria for Adverse Events in a multicenter trial: NCCTG N1048. J Clin Oncol 36. https://doi.org/10.1200/ JCO.2018.78.8620

64. Gilbertson-White S, Yeung CW, Saeidzadeh S, Tykol H, Vikas P, Cannon A (2019) Engaging stakeholders in the development of an eHealth intervention for cancer symptom management for rural residents. J Rural Health 35:189-198

65. Duman-Lubberding S, van Uden-Kraan CF, Peek N, Cuijpers P, Leemans CR, Verdonck-de Leeuw IM (2015) An eHealth application in head and neck cancer survivorship care: health care professionals' perspectives. J Med Internet Res 17:e235

66. Duman-Lubberding S, van Uden-Kraan CF, Jansen F, Witte BI, van der Velden LA, Lacko M, Cuijpers P, Leemans CR, Verdonck-de Leeuw IM (2016) Feasibility of an eHealth application "OncoKompas" to improve personalized survivorship in cancer care. Support Care Cancer 24:2163-2171

67. Melissant HC, Verdonck-de Leeuw IM, Lissenberg-Witte BI, Konings IR, Cuijpers P, van Uden-Kraan CF (2018) 'Oncokompas', a web-based self-management application to 
support patient activation and optimal supportive care: a feasibility study among breast cancer survivors. Acta Oncol 57:924-934

68. van der Hout A, van Uden-Kraan CF, Witte BI, Coupé VMH, Jansen F, Leemans CR, Cuijpers P, van de Poll-Franse LV, Verdonck-de Leeuw IM (2017) Efficacy, cost-utility and reach of an eHealth self-management application 'Oncokompas' that helps cancer survivors to obtain optimal supportive care: study protocol for a randomised controlled trial. Trials 18:228

69. Weaver A, Young AM, Rowntree J, Townsend N, Pearson S, Smith J, Gibson O, Cobern W, Larsen M, Tarassenko L (2007) Application of mobile phone technology for managing chemotherapy-associated side-effects. Ann Oncol 18:1887-1892

70. Larsen ME, Rowntree J, Young AM et al (2008) Chemotherapy side-effect management using mobile phones. Conf Proc IEEE Eng Med Biol Soc 2008:5152-5155

71. Yap KY, Low HX, Koh KS et al (2013) Feasibility and acceptance of a pharmacist-run tele-oncology service for chemotherapy-induced nausea and vomiting in ambulatory cancer patients. Telemed J E Health 19:387-395

72. Kroenke K, Theobald D, Norton K, Sanders R, Schlundt S, McCalley S, Harvey P, Iseminger K, Morrison G, Carpenter JS, Stubbs D, Jacks R, Carney-Doebbeling C, Wu J, Tu W (2009) The Indiana Cancer Pain and Depression (INCPAD) trial design of a telecare management intervention for cancer-related symptoms and baseline characteristics of study participants. Gen Hosp Psychiatry $31: 240-253$

73. Kroenke K, Theobald D, Wu J, Norton K, Morrison G, Carpenter J, $\mathrm{Tu} \mathrm{W}$ (2010) Effect of telecare management on pain and depression in patients with cancer: a randomized trial. JAMA 304:163-171

74. Timmerman JG, Dekker-van Weering MGH, Stuiver MM et al (2017) Ambulant monitoring and web-accessible home-based exercise program during outpatient follow-up for resected lung cancer survivors: actual use and feasibility in clinical practice. J Cancer Surviv 11:720-731

75. Wheelock AE, Bock MA, Martin EL, Hwang J, Ernest ML, Rugo HS, Esserman LJ, Melisko ME (2015) SIS.NET: A randomized controlled trial evaluating a web-based system for symptom management after treatment of breast cancer. Cancer 121:893-899

76. Yount SE, Rothrock N, Bass M, Beaumont JL, Pach D, Lad T, Patel J, Corona M, Weiland R, del Ciello K, Cella D (2014) A randomized trial of weekly symptom telemonitoring in advanced lung cancer. J Pain Symptom Manag 47:973-989

77. Mooney KH, Beck SL, Wong B, Dunson W, Wujcik D, Whisenant M, Donaldson G (2017) Automated home monitoring and management of patient-reported symptoms during chemotherapy: results of the symptom care at home RCT. Cancer Med 6:537-546

78. Kolb NA, Smith AG, Singleton JR, Beck SL, Howard D, Dittus K, Karafiath S, Mooney K (2018) Chemotherapy-related neuropathic symptom management: a randomized trial of an automated symptom-monitoring system paired with nurse practitioner follow-up. Support Care Cancer 26:1607-1615

79. Rocque GB, Halilova KI, Varley AL, Williams CP, Taylor RA, Masom DG, Wright WJ, Partridge EE, Kvale EA (2017) Feasibility of a telehealth educational program on self-management of pain and fatigue in adult cancer patients. J Pain Symptom Manag 53:1071-1078
80. Nimako K, Lu SK, Ayite B, Priest K, Winkley A, Gunapala R, Popat S, O'Brien MER (2013) A pilot study of a novel home telemonitoring system for oncology patients receiving chemotherapy. J Telemed Telecare 19:148-152

81. Williams AR, Williams DD, Williams PD, Alemi F, Hesham H, Donley B, Kheirbek RE (2015) The development and application of an oncology therapy-related symptom checklist for adults (TRSC) and children (TRSC-C) and e-health applications. Biomed Eng Online 14:S1

82. Graetz I, Anderson JN, McKillop CN et al (2018) Use of a webbased app to improve postoperative outcomes for patients receiving gynecological oncology care: a randomized controlled feasibility trial. Gynecol Oncol 150:311-317

83. Ruland CM, Andersen T, Jeneson A, Moore S, Grimsbø GH, Børøsund E, Ellison MC (2013) Effects of an internet support system to assist cancer patients in reducing symptom distress: a randomized controlled trial. Cancer Nurs 36:6-17

84. Børøsund E, Cvancarova M, Ekstedt M, Moore SM, Ruland CM (2013) How user characteristics affect use patterns in web-based illness management support for patients with breast and prostate cancer. J Med Internet Res 15:e34

85. Børøsund E, Cvancarova M, Moore SM, Ekstedt M, Ruland CM (2014) Comparing effects in regular practice of e-communication and web-based self-management support among breast cancer patients: preliminary results from a randomized controlled trial. J Med Internet Res 16:e295

86. Marthick M, Dhillon HM, Alison JA, Cheema BS, Shaw T (2018) An interactive web portal for tracking oncology patient physical activity and symptoms: prospective cohort study. JMIR Cancer 4: e11978

87. Denis F, Basch E, Septans AL, Bennouna J, Urban T, Dueck AC, Letellier C (2019) Two-year survival comparing web-based symptom monitoring vs routine surveillance following treatment for lung cancer. JAMA 321:306-307

88. Strasser F, Blum D, von Moos R, Cathomas R, Ribi K, Aebi S, Betticher D, Hayoz S, Klingbiel D, Brauchli P, Haefner M, Mauri S, Kaasa S, Koeberle D (2016) The effect of real-time electronic monitoring of patient-reported symptoms and clinical syndromes in outpatient workflow of medical oncologists: E-MOSAIC, a multicenter cluster-randomized phase III study (SAKK 95/06). Ann Oncol 27:324-332

89. Cherny NI, Dafni U, Bogaerts J, Latino NJ, Pentheroudakis G, Douillard JY, Tabernero J, Zielinski C, Piccart MJ, de Vries EGE (2017) ESMO-magnitude of clinical benefit scale version 1.1. Ann Oncol 28:2340-2366

90. Atema V, van Leeuwen M, Oldenburg HSA, van Beurden M, Hunter MS, Aaronson NK (2017) An internet-based cognitive behavioral therapy for treatment-induced menopausal symptoms in breast cancer survivors: results of a pilot study. Menopause 24: 762-767

91. Alberts NM, Hadjistavropoulos HD, Dear BF, Titov N (2017) Internet-delivered cognitive-behaviour therapy for recent cancer survivors: a feasibility trial. Psychooncology 26:137-139

Publisher's note Springer Nature remains neutral with regard to jurisdictional claims in published maps and institutional affiliations. 